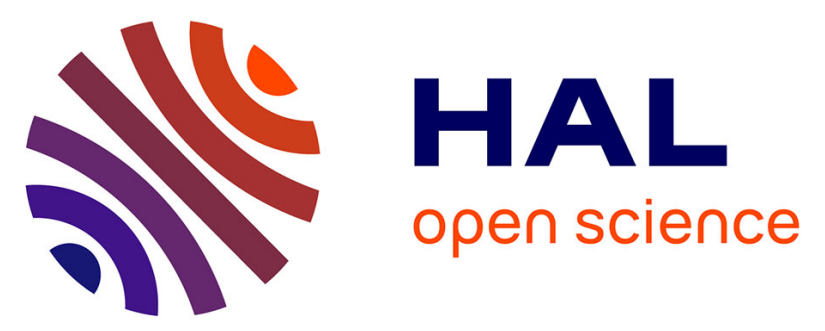

\title{
Environmental analysis of polar and non-polar Polycyclic Aromatic Compounds in airborne particulate matter, settled dust and soot: Part II: Instrumental analysis and occurrence
}

Mathieu Galmiche, Olivier Delhomme, Yannis-Nicolas François, Maurice Millet

\section{To cite this version:}

Mathieu Galmiche, Olivier Delhomme, Yannis-Nicolas François, Maurice Millet. Environmental analysis of polar and non-polar Polycyclic Aromatic Compounds in airborne particulate matter, settled dust and soot: Part II: Instrumental analysis and occurrence. Trends in Analytical Chemistry, 2021, 134, pp.116146. 10.1016/j.trac.2020.116146 . hal-03408194

\author{
HAL Id: hal-03408194 \\ https://hal.science/hal-03408194
}

Submitted on 23 Nov 2021

HAL is a multi-disciplinary open access archive for the deposit and dissemination of scientific research documents, whether they are published or not. The documents may come from teaching and research institutions in France or abroad, or from public or private research centers.
L'archive ouverte pluridisciplinaire HAL, est destinée au dépôt et à la diffusion de documents scientifiques de niveau recherche, publiés ou non, émanant des établissements d'enseignement et de recherche français ou étrangers, des laboratoires publics ou privés. 
1 Environmental analysis of polar and non-polar Polycyclic Aromatic

2 Compounds in airborne particulate matter, settled dust and soot: Part II:

3 Instrumental analysis and occurrence

4

Mathieu Galmiche ${ }^{\mathrm{a}, \mathrm{b}}$, Olivier Delhomme $\mathrm{a,c}$, Yannis-Nicolas François ${ }^{\mathrm{b}}$, Maurice Millet $\mathrm{a}^{*}$

a Institut de Chimie et Procédés pour l'Energie, l'Environnement et la Santé (ICPEES) - Physicochimie de l'atmosphère, Université de Strasbourg - CNRS, UMR 7515

25 rue Becquerel, 67087 Strasbourg Cedex 3, France

b Laboratoire de Spectrométrie de Masse des Interactions et des Systèmes, Université de Strasbourg - CNRS, UMR 7140

4 rue Blaise Pascal, 67081 Strasbourg Cedex, France

c UFR Sciences fondamentales et appliquées, Université de Lorraine

Campus Bridoux, rue du Général Deslestraint, 57070 Metz, France

* corresponding author: mmillet@unistra.fr 


\section{Abstract}

Interests in PAHs and their derivatives (NPAHs, OPAHs, Azaarenes and PASHs) have been growing because of their toxicity.

The second part of this review gathers information on the separation and detection of Polycyclic Aromatic Compounds (PACs) and on their occurrence levels in airborne particulate matter, dust and soot.

Chromatography is used to separate PACs before their identification and quantification. For both GC and LC, the choice of the stationary phase is crucial to obtain good resolution of PACs, which can be difficult when a lot of compounds are included in the same analysis. Mass Spectrometry is ideal for PACs detection. It can be hyphenated to both GC and LC, is applicable to all subclasses of PACs and its sensitivity and specificity enables environmental assessment of ultratrace levels.

PACs are generally around the $\mathrm{ng} \cdot \mathrm{m}^{-3}$ level in atmospheric PM and at several $\mu \mathrm{gg}^{-1} \mathrm{~g}^{-1}$ in dust and soot. Some geographical and seasonal trends of their occurrence can be highlighted.

Keywords

41 PAHs, Nitrated PAHs, Oxygenated PAHs, Azaarenes, PASHs, Gas Chromatography, Liquid 


\section{Introduction}

Polycyclic Aromatic Hydrocarbons (PAHs) mainly occur in the environment due to incomplete combustion processes, either related to natural sources such as wildfires, volcanism, etc. [13] or more frequently to anthropogenic sources such as industrial processes, fuel combustion, vehicular transport, tobacco smoking, cooking, etc. [1-6]. PAHs sources can be identified thanks to individual "tracer" $\mathrm{PAHs}$, diagnostic ratios, or thorough statistical studies [6-10].

PAHs have been reported as major hazardous compounds in various environments for decades. From the 1970s, efforts have been made in the United States of America to define a list of priority pollutants, finally resulting in the well-known U.S. EPA's 16 PAH Priority Pollutants list [11]. However, this list omits some very potent pollutants, either high molecular weight (HMW) non-polar PAHs, alkylated PAHs, or polar Polycyclic Aromatic Compounds (PACs) [12].

Among those polar PACs, nitrated PAHs (NPAHs) and oxygenated PAHs (OPAHs) are the most studied [13-15]. Their formation can result from reactions between "parent" PAHs and oxidative agents in the environment, especially in indoor and outdoor air, as well as in atmospheric particulate matter $(\mathrm{PM})$, where hydroxyl radical $(\mathrm{OH} \cdot)$, ozone $\left(\mathrm{O}_{3}\right)$, and nitrogen oxides $\left(\mathrm{NO}_{\mathrm{x}}\right)$ reactivities play a crucial role $[1,2,16,17]$. They can also be directly released in the environment by the same kind of combustion processes as those responsible for PAHs occurrence: burning of coal or wood for heating and cooking, industrial processes, vehicular emissions, etc. [1,13-15,18-21].

Source apportionment of polar PACs has been studied with particular tracers such as 1nitropyrene, typical of diesel emissions, or 2-nitropyrene and 2-nitrofluoranthene, typical of secondary formation from their parent PAH. Based on this knowledge, some diagnostic ratios have been implemented to characterize the main origins of such PACs in a complex samples, as well as for PAHs, mainly to characterize primary versus secondary formation of NPAHs [13,20-24]. Another approach to assess the predominance of primary or secondary formation of PAHs derivatives is to study the ratio of the sum of OPAHs or NPAHs to the sum of parent PAHs and alkylated PAHs [19].

In addition to NPAHs and OPAHs, other polar PACs are of a growing interest: azaarenes (AZAs), sometimes alternatively referred to as Polycyclic Aromatic Nitrogen Heterocycles (PANHs), and Polycyclic Aromatic Sulfur Heterocycles (PASHs). While AZAs are quite 
similar to the above-mentioned PAHs, NPAHs and OPAHs in terms of sources and toxicology [25-27], PASHs are particularly typical of petrogenic emissions and have been studied sooner in the evolution of environmental analysis of PACs [28,29]. Both categories have also been studied by the IARC and some of their compounds have been classified as possible or probable carcinogens [30].

Naturally, all these different compounds of interest lead to analytical complexity if one wants to gather them in a single analytical method.

After having discussed sampling of particulate samples and extraction of PACs from these matrices in the first part of our article, we will here review the state of the art and the perspectives of instrumental analysis of PACs, in terms of separation and detection. Typical concentrations reported in the literature for the different classes of PACs will also be given.

\section{Separation: Chromatography}

Nowadays, analytical methods focused on the PAC content of particulate matters rely on a chromatography step whose aim is to separate the individual compounds belonging to the various PAC categories in order to quantify them. This involves many challenges, considering:

- the high complexity of such environmental matrices in terms of chemical composition (interferences can be expected even after sample clean-up)

- the high amount of compounds, including isomers, composing each of the PAC classes mentioned in this article. There is a significant risk of quantifying by mistake several individual compounds together if the chromatography method is not efficient enough.

In this section, we will discuss the application of both gas and liquid chromatography for the determination of polar and non-polar PACs.

\subsection{Gas chromatography (GC)}

GC is the most widely used separation technique for the determination of PACs. It is of a particular interest for this family of compounds because of its ability to separate structural isomers thanks to their difference in boiling point, whereas it can be tough to resolve them based on their chemical affinity with a stationary phase of liquid chromatography (LC), which is frequently identical for structural isomers. 
The application of GC for PACs determination has been developed for decades. With the technical developments of gas chromatography, protocols have evolved towards almost standardized methods.

At least, some highlights and common points between the vast majority of GC methods for PACs can be noted: the use of polysiloxane capillary columns, the use of an inert carrier gas, usually helium, at flow rates from 1.0 to $1.5 \mathrm{~mL} \cdot \mathrm{min}^{-1}$, and temperature programs ranging from 40 to $100^{\circ} \mathrm{C}$ at the beginning of the run and from 270 to $325^{\circ} \mathrm{C}$ at the end of the run. The chosen column is in the vast majority of cases a capillary column of length $30 \mathrm{~m}$, diameter $0.25 \mathrm{~mm}$, and film thickness $0.25 \mu \mathrm{m}$ [31-36]. Less usual alternatives to these dimensions are $60 \mathrm{~m}$ columns [29,37-39] or even more rarely shorter lengths (15 m, $12 \mathrm{~m}$ ) $[40,41]$.

Another option is the use of thinner liquid films $(0.1-0.15 \mu \mathrm{m})$, to decrease the retention of the less volatile PACs, to improve peak shapes and to decrease background noise $[37,41]$.

Similarly to guard columns in LC methods, retention gaps can be inserted between the injector and the GC analytical column. These retention gaps are designed to retain nonvolatile compounds, thus minimizing contamination of the column, and to reconcentrate analytes for a better peak shape $[42,43]$. They are made up of uncoated, deactivated fused silica capillaries of 0.25 to $0.5 \mathrm{~mm}$ diameter and 2 to $5 \mathrm{~m}$ length.

In the subsections below, we detail the typical parameters and the main issues of a GC method development for the different groups of PACs.

\subsubsection{PAHs}

PAHs have been the most studied PACs in a lot of different environmental samples. For particulate matrices alone, dozens of articles using GC for the determination of PAHs can be found in the literature. This led to the standardization of PAH analysis methods in the United States of America as well as in Europe, with a choice to promote GC as the separation technique in these standards [44-47]. It can explain the relative uniformity in various methods developed for the analysis of PAHs in particulates.

For what regards the stationary phase of the columns, a global consensus is the use of nonpolar $5 \%$ phenyl - 95\% dimethylpolysiloxane, that we can almost qualify as universal $[32,34,35,39,48]$.

However, it can still be interesting to test other phases, as shown by the study of Sauvain et al. who reported a better resolution of benzofluoranthene $b$, j and $k$ isomers and of 
dibenzopyrene $[\mathrm{a}, \mathrm{e}],[\mathrm{a}, \mathrm{i}]$ and $[\mathrm{a}, \mathrm{h}]$ isomers on a medium polarity column : $50 \%$ phenyl $-50 \%$ dimethylpolysiloxane [43]. Such a stationary phase was also used with success for the determination of PAHs, OPAHs and PASHs by Wang et al. [49]. Similarly, Sklorz et al. were not enable to resolve chrysene and triphenylene, as well as $b$ and $j$ isomers of benzofluoranthene, and dibenz[a,h]anthracene and indeno[1,2,3-cd]pyrene on a $5 \%$ phenyl column [50]. For these reasons, Poster et al. considered 50\% phenyl - 50\% methyl polysiloxane columns as the best choice for GC resolution of PAHs in their review [42]. In several works, analysts of the National Institute of Standards and Technology presented the use of liquid crystalline columns for the separation of PAHs, a solution offering a unique selectivity based on molecular shape [51,52]. But because of its poor thermal stability, and of the huge development of capillary polysiloxane columns, this phase has not been widely applied in other recent works and is no longer commercially available [53].

The injection of liquid extracts in the GC instrument has not been stated as a major issue in related articles. It is often performed with "classical" parameters, i.e. temperatures above $250^{\circ} \mathrm{C}$, up to $320^{\circ} \mathrm{C}[54-56]$.

In spitless mode, a pressure pulse can be applied to "push" the sample and reduce peak broadening. When around one minute of injection is completed, the split valve should be reopened to avoid clogging of the injector.

The split ratio applied in the injector usually depends on the expected PAHs concentrations and matrix contaminations: the more concentrated the PAHs in the sample and the more highly loaded the matrix, the higher the applied split ratio. The majority of the developed methods involve splitless mode, but split ratios up to 1:20 can be expected [32-34,56,57]. Nonetheless, Poster et al. rather advised for cold on-column (COC) injection for PAH analysis, stating that the resolution of low-molecular-mass PAHs could be improved [42]. Programmable Temperature Vaporizer (PTV) can also be interesting, as it enables to inject larger volumes when expected levels are very low, and protects thermolabile compounds by heating and vaporizing them progressively. Scipioni et al. have implemented PTV for the simultaneous determination of PAHs and NPAHs (which are more sensitive than PAHs) [58]. Norlock et al. applied successfully PTV-GC-MS to 16 PAHs, demonstrated the enhancement of sensitivity thanks to higher injected volumes, and detailed the critical PTV parameters to improve sensitivity and robustness of the method [59].

\subsubsection{OPAHs}


Several categories of oxygenated PAHs should be distinguished: this class is composed of carbonyl, hydroxyl and carboxyl PAHs. Among those, only carbonyl PAHs, i.e. ketones and quinones, can be directly analyzed by GC.

On the other hand, carboxyl and hydroxyl PAHs require derivatization (silylation) in order to increase their volatility and thermal stability. This derivatization step is usually performed with N,O-bis-(trimethylsilyl)trifluoroacetamide (BSTFA) and trimethylchlorosilane (TCMS) to obtain the trimethylsilyl derivatives (ethers or esters) [60-62]. Another possibility is to use pentafluorobenzoyl chloride (PFBCl), as presented by Lin et al. [41]. In this case, hydroxyl functions are acylated.

Because of the polar character of OPAHs, the choice of the best stationary phase requires more consideration for OPAHs determination than for PAHs. Indeed, $5 \%$ phenyl and $50 \%$ phenyl phases have both been implemented by various labs [17,49,60,63,64]. Nocun and Schantz compared polar DB-17ms (50\% phenyl) with non-polar DB-XLB and reported a better resolution on the more polar column, whereas several compounds such as 1,4-phenantrenequinone, 9,10-anthraquinone, benzofluorenone, benzanthrone and cyclopentaphenanthrenone could not be quantified on the DB-XLB column because of coelutions [38]. The same co-elution between 1,4-phenantrenequinone and 9,10-anthraquinone was reported by Liu et al. [65].

These results tend to orient the column choice towards intermediate polarity columns for OPAHs.

The sample injection is not anecdotal in the case of OPAHs. Indeed, there is a risk of thermal degradation of OPAHs during injection at high temperature, as reported by various groups for different compounds such as phenanthrenequinone or acenaphthenequinone $[38,65]$. Because of this, Nocun and Schantz implemented cold on-column injection [38]. Similarly, Albinet and co-workers developed methods with cool injections either programmed from 40 to $320^{\circ} \mathrm{C}(\mathrm{PTV})$ or set at $140^{\circ} \mathrm{C}[31,63]$.

Yet, there is still a majority of works on OPAHs which report classical splitless injections at temperatures above $250^{\circ} \mathrm{C}[33,60,66-68]$.

\subsubsection{NPAHs}

In the case of nitrated PAHs GC separation, reference works have been published by the groups of Holly A. Bamford and Dawit Z. Bezabeh in the United States $[69,70]$. In their articles, they presented a comparison of $5 \%$ phenyl and $50 \%$ phenyl stationary phases for resolution of NPAHs. On the less polar columns such as $5 \%$ phenyl, 2-nitrofluoranthene and 
3-nitrofluoranthene cannot be satisfyingly resolved. This is troublesome because they are often used as tracers of primary vs. secondary formation of NPAHs, so they need to be reliably quantified individually (see Section 4.3.). Bamford et al. reported a better separation of nitrofluoranthene isomers on $50 \%$ phenyl columns [69]. In addition, other isomers such as those of nitropyrene, nitroanthracene and nitrophenanthrene showed a better resolution on these more polar columns, encouraging the use of such stationary phases. However, the same authors reported the poor resolution of nitrobenzo[a]pyrene and nitrobenzo[e]pyrene on a 50\% phenyl column. For this reason, Albinet et al. chose to work on a $5 \%$ phenyl column. They wanted to study closely the degradation products of benzo[a]pyrene which is the reference compound in terms of toxicity for PACs [31]. Therefore, the definition of priority compounds in an analytical study of NPAHs is the key factor to settle the choice of the GC column. This explains why, similarly to what we described for OPAHs, both $5 \%$ phenyl $[31,58,64,71]$ and $50 \%$ phenyl $[36,56]$ columns have been implemented in NPAHs studies.

Another similarity between OPAHs and NPAHs is the risk of degradation in the injector. This was stated, among others, by Albinet et al. who chose to perform cool injections in their studies on polar PAHs derivatives [31,63], and by Zielinska and Samy in their review of the early works about nitrated PAHs [24]. Cool injections were also advised by Bamford et al. in what we called above a "reference work" [69].

Apart from Scipioni et al. and Tutino et al. who implemented a PTV injector from 90 to $290^{\circ} \mathrm{C}$ and from 50 to $300^{\circ} \mathrm{C}$, respectively, so that degradation of the most volatile and thermosensitive NPAHs could be avoided [36,58], most of the recent analytical methods still rely on traditional injections above $250^{\circ} \mathrm{C}[41,56,66]$. These injections should be performed in splitless mode, because concentrations of NPAHs in particulates are usually very low, so injection parameters should be chosen to enhance the sensitivity.

\subsubsection{AZAs}

Although interests in this class of compounds showed up relatively early in the history of environmental analysis of PACs, especially by gas chromatography [72,73], only a few works report the analysis of azaarenes. For these compounds, one can consider the article of Chen and Preston from 1998 as a reference. In their study, they detected as much as 47 azaarenes individuals in ambient aerosol samples, and the separation was performed with a non-polar 5\% phenyl stationary phase [25].

A few years later, Sauvain et al. compared 5\% phenyl and $50 \%$ phenyl stationary phases without observing a major difference in terms of recovery for the three studied AZAs [43]. 
The work of Delhomme and Millet in 2008 had the purpose of comparing the performance of GC and LC for azaarenes determination. Their stationary phase was trifluoropropylmethyl polysiloxane, and enabled to separate 20 different azaarenes in less than 30 minutes, with slight overlaps for the dibenzacridine isomers but still a better resolution than the one obtained with the LC method, as presented in Figure 1. This work can therefore be considered as a good starting point for the development of a method targeting AZAs [74]. Vicente et al. and Alves et al. included quinoline, benzo[h]quinoline, acridine and carbazole in their analysis campaigns of PAHs and derivatives in atmospheric PM, based on the GC method developed by Bandowe and Wilcke for PAHs and OPAHs, involving the use of a classical $5 \%$ phenyl column $[60,75,76]$.

In the works of Delhomme and Millet, Vicente et al. and Alves et al. mentioned above, injections were performed classically, at a temperature of $280^{\circ} \mathrm{C}$, and no potential degradation of the AZAs was reported [74-76]. Only Sauvain et al. chose to inject their samples with a temperature ranging from 40 to $300^{\circ} \mathrm{C}$ in the course of the injection [43].

\subsubsection{PASHs}

Reference works for the GC separation of PASHs have been based on the analysis of fossil fuel or coal-tar SRMs [29,77]. In both of these articles, authors presented comparisons of different stationary phases. Their conclusions were consistent, because both studies reported the better suitability of polar columns for the resolution of PASHs.

Schmid and Andersson observed coelutions of dibenzothiophene with naphtho[1,2b]thiophene and of phenanthrene with naphtho[2,1-b]thiophene on a low-polarity column (30\% biphenyl), but these compounds were well resolved on a polar column $(100 \%$ cyanopropyl) [77].

Mössner and Wise also reported this same coelution between dibenzothiophene and naphtho[1,2-b]thiophene on the non-polar DB-5MS, a problem solved with the use of a $50 \%$ phenyl column [29].

On the other hand, Zeigler et al. studied retention behaviors of PASHs on various columns, and did not quite reach the same results. They stated the coelution of dibenzothiophene with naphtho[1,2-b]thiophene both on the 5\% phenyl and on 50\% phenyl column. Among the four stationary phases they compared, the lowest proportion of coelutions was obtained on a trifluoropropylmethyl phase, followed by the $5 \%$ phenyl and the cyanopropylmethyl phases [78]. 
Following these statements, part of the GC methods for PASHs separation in the literature involve the use of polar columns [49,79], and another part the use of non-polar columns $[40,80,81]$. Anyway, the coeluting molecules should be known in advance or searched carefully in order to avoid analytical errors. Moreover, according to Andersson et al., even keeping the same phase, results can be different depending on the commercial column used and some coelutions can be fixed by using a different column of the same category [82]. Wilson et al. listed some other examples of stationary phases used to resolve PASHs such as $50 \%$ liquid crystalline-dimethylpolysiloxane and poly-cationic ionic liquids, but these are far less current [53].

To our knowledge, no particular issue has been described until now concerning a suspected thermal sensibility of SPAHs during the injection. Zeigler et al. reported both injections with a classical injector at $300^{\circ} \mathrm{C}$ and with a PTV heated from 20 to $300^{\circ} \mathrm{C} \mathrm{[78].} \mathrm{The} \mathrm{former} \mathrm{solution}$ was applied by Liang et al. at $280^{\circ} \mathrm{C}$, the latter by Vu-Duc et al. from 40 to $300^{\circ} \mathrm{C}[79,81]$.

\subsection{Liquid chromatography (LC)}

LC offers the advantage of enabling analysis of lowly volatile and/or thermo-sensitive compounds. This can be very interesting in the case of OPAHs or NPAHs, as explained above.

However, the resolving power of LC methods is not consistently as good as the one of GC methods, especially for isomers [74]. Moreover, an important difference between both techniques when it comes to multiresidue analysis of complex samples is the lower peak capacity of LC which makes the determination of a high amount of different molecules difficult [42].

Studies reporting the use of LC to separate and quantify PACs in particulates generally rely on a separation on reversed-phase $\mathrm{C}_{18}$ stationary phases with acetonitrile/water or methanol/water mobile phases operated in gradient mode with decreasing proportion of water. Regarding other parameters, in most of the studies the column is not heated above $35^{\circ} \mathrm{C}$ and volumes injected are between 15 and $25 \mu \mathrm{L}$.

Several works advise for the use of a guard column to clean further up the sample before its separation on the analytical column in order to preserve the analytical equipment. This guard column should be composed of a stationary phase similar to the one of the analytical column (i.e. $\mathrm{C}_{18}$ ), with a similar diameter and particle size. Its length is usually around $10 \mathrm{~mm}[83,84]$. Further details on this "general scheme" are discussed below. 
As reported by Poster et al. in their review, both LC and GC methods are applied in standard analytical methods approved by US federal agencies for the determination of PAHs [42]. For instance, the EPA Method 610 is able to resolve all of the 16 EPA's PAHs, whereas the GC column described together with this LC method does not adequately resolve as much as four pairs of PAHs: anthracene and phenanthrene; chrysene and benz[a]anthracene; benzo[b]fluoranthene and benzo[k]fluoranthene; dibenz[a,h]anthracene and indeno[1,2,3cd]pyrene [42]. Nonetheless, these results are to be balanced by the use of a $1.8 \mathrm{~m} \times 2 \mathrm{~mm}$ GC glass column packed with 3\% OV-17 (50\% phenyl methylsilicone) instead of a capillary column, which we now know as more effective, in this EPA Method 610. In their comparison of GC-MS and LC-FD (see the subsection on fluorescence detection, 3.2.2.), Wise et al. stated that the first technique is very selective and enables a determination without too much sample handling and upstream clean-up, whereas LC requires more clean-up, but coupled detection techniques such as fluorescence can differentiate some isomers, which is not the case with classical Single lon Monitoring (SIM) detection in GC-MS. In their study, GC-MS and LC-FD provided comparable results [85]. The choice of the most suitable analytical technique depends on the priority compounds researched: benz[a]anthracene, anthracene and perylene present a more sensitive and selective detection by LC-FD, whereas GC-MS is more interesting for benzo[ghi]perylene for example [42]. As stated in section 2.1.1, GC on capillary columns remains the more common method for $\mathrm{PAH}$ analysis.

If $\mathrm{LC}$ separation is wished, $\mathrm{C}_{18}$ is the most appropriate stationary phase, and several suppliers have developed reversed-phases based on cross-linked $\mathrm{C}_{18}$ which display a particular specificity for PAHs separation [37,84,86-88]. The typical dimensions of these columns are between 3.0 and $4.6 \mathrm{~mm}$ diameter, between 50 and $250 \mathrm{~mm}$ length, and between 4.0 and $5.0 \mu \mathrm{m}$ particle size.

Of course, the recent technological developments encourage the implementation of UltraHigh Performance Liquid Chromatography (UPLC), for which columns have smaller diameters $(<2.5 \mathrm{~mm})$ and particle sizes $(<2 \mu \mathrm{m})[37,88]$.

Elution programs are all based on a mobile phase composed of water with acetonitrile or methanol, flowing at a rate of 0.8 to $1.5 \mathrm{~mL} \cdot \mathrm{min}^{-1}$. The proportion of the less polar solvent is usually set to increase from 40 to $50 \%$ at the beginning of the run to $100 \%$ at the end of the program to ensure the elution of non-polar PAHs. Depending on the number of target 
compounds and on the complexity of the matrix, run times can vary from half an hour to an hour, broadly speaking [86-89].

\subsubsection{OPAHs}

LC can be very interesting for the analysis of hydroxyl and carboxyl PAHs which require derivatization to be separated by gas chromatography (see Section 2.1.2). Thanks to LC, they can be directly analyzed [90,91]. Another advantage of this method for hydroxyl PAHs is their good sensitivity to fluorescence detection.

Moreover, LC is also suitable for ketones and quinones analysis [92-94]. Thus, Letzel et al. have been able to analyze acids, lactones, hydroxides, ketones, quinones and hydroxyquinones derivatives of PAHs together by LC-APCI-MS [95].

$\mathrm{C}_{18}$ phases generally offer a good separation efficiency, but Letzel et al. reported coelutions of the most polar degradation products of benzo[a]pyrene on such columns. Therefore, they have compared in their study four types of stationary phases: octadecyl $\left(\mathrm{C}_{18}\right)$, octyl $\left(\mathrm{C}_{8}\right)$, ethyl $\left(\mathrm{C}_{2-3}\right)$, cyanopropyl $(\mathrm{CN})$ and phenyl $\left(\mathrm{C}_{6} \mathrm{H}_{5}\right)$ [93]. They concluded that the best results were obtained with the phenyl column, because the polar substances could be separated in less than 30 minutes with a methanol/water gradient and kept this phase for further studies $[93,96]$. In these studies, they reported a general elution scheme of OPAHs in decreasing order of polarity: carboxylated $\mathrm{PAHs}<$ dihydroxylated $\mathrm{PAHs}<$ hydroxylated $\mathrm{PAHs} \approx<\mathrm{PAH}$ quinones $<\mathrm{PAH}$ ketones. They added that inside a sub-category of compounds, the retention time increases with increasing size of aromatic system. These statements are perfectly consistent with the expectations in the case of reversed phase liquid chromatography.

Delhomme et al. proposed two different gradients for the separations of ketones and for the separation of diketones (quinones): from 60 to $100 \%$ methanol in 8.5 minutes and from $30 \%$ to $100 \%$ methanol in 30 minutes, respectively [92].

The run time highly depends on the number of different compounds included in the method. Whereas Barrado-Olmedo et al. determined their two only compounds of interest, 1hydroxypyrene and 2-hydroxyphenanthrene, in 7 minutes in isocratic conditions, Lintelmann et al. needed 47 minutes to separate their 10 OPAHs and 17 PAHs $[90,94]$.

\subsubsection{NPAHs}


A major drawback of NPAHs for the implementation of their LC determination is their poor fluorescence sensitivity (see section 3.2.). Therefore, they require post-column reduction to be analyzed by LC-FD, and similar LC systems with post-column reactions also need to be set up if chemiluminescence is chosen as detection method. To this end, Hayakawa et al. developed a method, later taken over in studies of Kojima et al. and Pham et al. among others, involving four pumps, a pre-column, two analytical columns and a post-column chemiluminescence reaction system $[17,83,97]$. Such systems require multiple pumps, columns, switching valves, etc. This represents an important technical complexity and several problems to solve during the method development and during the routine operation of the method.

Furthermore, the peaks obtained after LC separation and derivatization of NPAHs in a supplemental column can be broad. This leads to overlaps of peaks and even coelutions, in addition to a higher uncertainty in the quantification.

This is why the choice of mass spectrometry (MS) as detection technique after LC separation of NPAHs has gained a lot of interest [13,98].

$\mathrm{C}_{18}$ phases enable the resolution of a lot of NPAHs, even if in studies where many different NPAHs are separated (especially in higher mass ranges), reported run times are relatively long $[89,90,97,99]$.

Apart from post-column reagents required for the detection of the analytes, mobile phases for NPAHs analysis are similar to those described for PAHs and OPAHs analysis: methanol/water or acetonitrile/water with proportions varying from 30 to $60 \%$ organic solvent at the beginning and from 90 to $100 \%$ organic solvent at the end of the run when a gradient is applied [90,99]. Isocratic elution procedures have also been proposed $[89,97]$.

Schauer et al. reported the successful use of a phenyl column with a methanol/water eluent for the separation of NPAHs, except for isomers of nitrobenzo[a]pyrene which could not be resolved. The total run time for the determination of 15 individual NPAHs in their conditions was around 50 minutes [98]. As they used the same stationary phase as Letzel et al. for OPAHs (see Section 2.2.2), they could compare the retention behavior of NPAHs with the one of OPAHs, and concluded that the increase of retention time with molecular mass inside the NPAHs category was very similar to the observations of Letzel et al. on OPAHs [93,98]. Adding NPAHs and NPAHs quinones to the previous model, the following order of increasing retention time for polar PAHs derivatives on reversed-phase columns was described: NPAHs quinones < dihydroxylated PAHs < hydroxylated PAHs $<$ NPAHs $\approx$ PAH quinones. 
It is interesting to note that in this study of Schauer et al., results obtained for the measurement of diesel soot SRM 1650a by HPLC-reduction-fluorescence deviated significantly from GC-NCI-MS results from previous works, without the possibility of pinpointing precisely the source of these variations for the authors [98]. This example highlights the variability of PACs determination depending on the chosen analytical method.

\subsubsection{AZAs}

Because of the very few existing publications on the topic of azaarenes analysis in environmental samples, we only have two articles to discuss in this section, those of Delhomme and Millet, and Lintelmann et al. [74,100].

Both relied on the same kind of LC column: $C_{18}$ phases with $250 \mathrm{~mm}$ length and $5 \mu \mathrm{m}$ particle size. Both reported similar run times for a similar number of analytes, respectively the separation of 13 analytes in 35 minutes and 17 analytes in 30 minutes. However, the elution program differed between these studies: whereas Delhomme and Millet started the separation from $70 \%$ methanol, Lintelmann et al. started from $5 \%$ methanol, but both final conditions were $100 \%$ methanol to ensure the elution of most retained compounds.

These works are also complementary because Delhomme and Millet implemented fluorescence as the detection method, and Lintelmann et al. presented the hyphenation of LC with APPI-MS/MS detection.

Delhomme and Millet described their GC method as more appropriate for the analysis of azaarenes because of a better separation than with the LC method, for which coelutions were noticed, particularly between phenanthridine and benzo[h]quinoline. These ones are clearly visible in Figure 1. Other coelutions were observed by Lintelmann et al. between isomers of dibenzacridine.

On the other hand, Delhomme and Millet reported that the detection limits of the LC method were lower than those of the GC method, highlighting a major benefit of LC-FD determination of azaarenes. But the problems of resolution, especially between isomers (see Figure 1), and of lesser specificity of the fluorescence detection, rather influence the choice of instrument in the favor of GC-MS, hence the higher amount of works reviewed in Section 2.1.4.

\subsubsection{PASHs}

The separation of PASHs in environmental samples is not frequently performed by HPLC either. As stated by Andersson et al., its relatively low resolving power complicates the analysis of complex samples when several different compounds are targeted, unless a prior fractionation of the PAC content of the sample is performed [82]. 
482 Still, Wilson et al. studied extensively the retention of PASHs on reversed-phase LC columns

483 [101]. Because PAHs and PASHs are comparable in terms of LC retention, $\mathrm{C}_{18}$ columns is 484 the more appropriate stationary phase for PASHs resolution by LC.

485 Wilson et al. classified the PASHs in six different categories from three to six rings and 486 defined retention models depending on the length-to-breadth ratios of the compounds, i.e. on 487 their molecular shape. Importantly, they could not resolve satisfyingly the three-ring PASHs, 488 i.e. dibenzothiophene, [1,2-b], [2,1-b] and [2,3-b] isomers of naphthothiophene. These 489 molecules were already defined as problematic in case of GC separation (see Section 2.1.5), 490 but the results of Wilson et al. showed no improvement when LC was used. Several other 491 coelutions were observed for bigger PASHs [101].

\subsection{Two-dimensional chromatography}

Samples such as airborne particulate matter or diesel exhaust particulate matter show a very high chemical complexity. In particular, PACs which are widely present in these matrices regroup hundreds of components, with variable molecular size, volatility or polarity. Therefore, although it is rarely implemented because of its high technical sophistication, comprehensive two-dimensional chromatography can be a solution to resolve various PACs which could not be determined reliably with classical LC or GC. In this purpose, various works using GCxGC or LCxGC systems have been published. They will be the topic of this section.

According to what we discussed in Section 2.1., it can be difficult to resolve simultaneously polar and non-polar PACs on the same GC column, or to find an ideal temperature program to resolve PAC isomers with very similar physicochemical properties. method where a lot of PAHs, OPAHs and NPAHs could be determined simultaneously, with very good limits of detection [102]. Manzano et al. developed the same kind of method, but added to their list of analytes PASHs and halogenated PAHs, which brought the number of analytes up to 85 [103]. hyphenation is the most commonly implemented, because the difference of polarity between the two columns enables to separate in the second dimension ( $50 \%$ phenyl column) groups 
of peaks which are known to coelute in the first dimension (5\% phenyl column). The same combination of $5 \%$ phenyl and $50 \%$ phenyl columns was used the other way round by Zeigler et al. for the resolution of 119 PASHs [78].

Manzano et al. proposed an even more orthogonal combination, between a liquid crystal column (LC-50) in the first dimension and a nano-stationary phase column (NSP-35) in the second dimension [104]. With this combination, they reported significantly shorter analysis times for complex PAH mixtures compared to $1 \mathrm{D} \mathrm{GC/MS}$ and potentially reduced sample preparation. They compared this method with the combination of $5 \%$ phenyl and $50 \%$ phenyl phases and advised for the LC-50 / NSP-35 system because of its better resolution and more accurate quantification of complex $\mathrm{PAH}$ mixtures in environmental samples, including extracts with no silica gel clean-up $[103,104]$. The lesser need of sample clean-up is another advantage of comprehensive GCxGC, which is able to resolve a higher number of compounds and is therefore less sensitive to matrix composition.

Even if the above-cited works offer promising possibilities, we should mention once again that GCxGC is far more difficult to implement than traditional one-dimension GC. It requires a lot of technical knowledge and a longer method development.

\subsection{2. $L C X G C$}

A Swedish research group has developed for years a LCxGC analytical system and applied it for the determination of PAHs [105,106] and AZAs [107] in various particulate matter samples and SRMs.

This uncommon hyphenation enabled Tollbäck et al. to separate AZAs in two groups, acridines and carbazoles, in the first dimension (LC with a polar dimethylaminopropyl phase), and then to resolve the different compounds of the carbazole group in the second dimension (GC with non-polar 5\% phenyl phase) after back-flush of the LC column. The time required for a complete analysis was less than 40 minutes. According to the authors, this system offers a far better sensitivity than if the LC fractionation is performed off-line, and the automation reduces sample handling and time consumption [107].

The instrumentation presented by Christensen et al. also relies on a polar column (nitrophenylpropyl) in the LC dimension, which was used for the fractionation of PAHs and aliphatic / olefinic / mono- and di-aromatic compounds, with application of a back-flush to recover the PAHs fraction, and then the injection of this fraction on a non-polar GC column (5\% phenyl) for separation and MS detection. The main instrumental difference between their work and the one of Tollbäck et al. was the use of PTV injector which offers a good reproducibility even when large volumes are to be injected [105]. 
556 Similarly to what we discussed with two-dimensional GC, the analytical possibilities of on-line

557 LC-GC are really interesting in terms of reducing interferences in complex samples and

558 enhancing sensitivity, but it requires much technical ability and experience for its

559 development and for troubleshooting on daily applications.

560 
562

563

564

565

566

567

568

569

570

571

572

573

574

575

576

577

578

579

580

581

582

583

584

585

586

587

588

589

590

591

592

593

594

595

596

597

\subsection{Mass Spectrometry (MS)}

\subsubsection{GC-MS}

In accordance with the observations reported in the previous section, gas chromatography can be considered as the major separation method for PACs.

Mass spectrometry is the preferable detection method after a GC separation, because it is universal and offers a combination of selectivity and sensitivity with which no other GC detector can compete.

In the GC-MS coupling, regardless of the target compounds, an ionization source is largely predominant over the others: Electron Ionization (EI). Among PACs, the prevalence of $\mathrm{El}$ is verified for PAHs, PASHs and AZAs [29,35,43,74,78,108].

Generally, the ionization energy is standardized at $70 \mathrm{eV}$, and the ionizing current, which is only rarely documented, is around $35 \mu \mathrm{A}[19,102]$. The El source temperature is commonly set at $230^{\circ} \mathrm{C}[48,53,60,78]$, but some works report a higher heating of the source, up to $300^{\circ} \mathrm{C}[36,102,109]$.

A possible justification for using a hotter source is the risk of deposition within the instrument of the less volatile analytes (such as HMW PAHs), which can rapidly cause decreases in sensitivity and reproducibility. To this purpose, Anderson et al. developed a "self-cleaning" ion source with in-source hydrogen injection and a coarser extraction lens, which they operated at $340^{\circ} \mathrm{C}$, therefore enhancing sensitivity and reproducibility [54].

The exception to the use of El for PACs ionization regards NPAHs. These compounds give higher MS responses when Negative Ion Chemical Ionization ( $\mathrm{NICl}$ ) is used instead of El. Indeed, according to Bezabeh et al., negative ions formation from NPAHs is favored over positive ions formation, and the electron-withdrawing character of the $\mathrm{NO}_{2}$ group promotes electron capture [70].

With methane $\left(\mathrm{CH}_{4}\right)$ as reagent gas in the source, highly electronegative compounds are readily ionized by resonance capture of the thermal electron, whose low energy induces very few fragmentation. $\mathrm{NICl}$ yields sensitivities two orders of magnitude greater than those obtained with EI [69]. Furthermore, it is particularly selective towards molecules bearing such electron-withdrawing groups, which leads to a great reduction of background noise and interferences [110]. Therefore, this ionization method has been implemented in lots of studies on NPAHs $[19,31,64,108,111]$. 
Yet, El can still be used to detect NPAHs with satisfying signals, though lower than those obtained with $\mathrm{NICl}[36,58,102,112]$. The use of $\mathrm{El}$ is appropriate in analytical methods associating NPAHs to other PACs.

$\mathrm{NICl}$ operating conditions are less standardized than El parameters. From the data gathered in our references, $\mathrm{NICl}$ electron energy can vary from $45 \mathrm{eV}$ to $207 \mathrm{eV}$ and source temperature from 150 to $300^{\circ} \mathrm{C}[19,31,61,71,108]$.

Electron Capture Negative Ionization (ECNI) has been reported by Lin et al. for the determination of NPAHs [41]. The main difference between $\mathrm{ECNI}$ and $\mathrm{NICl}$ is that the electrons responsible for the ionization of the analytes are not provided by a reagent gas in this case. In ECNI, the only role of the reagent gas is to decelerate the electrons from the filament to close to thermal energy. Nonetheless, considering that the ionization energies of $\mathrm{ECNI}$ and $\mathrm{NICl}$ are very close, the ion source conditions to achieve $\mathrm{ECNI}$ and $\mathrm{NICl}$ are identical, so both can compete in the same source for a single mass spectrometry acquisition [113].

The remaining PAC category which we did not mention above is OPAHs. Indeed, the electronic properties of these molecules make them appropriate to both $\mathrm{El}$ $[17,19,38,102,112]$ and $\mathrm{NICl}[31,64,71,111]$.

They can be included in GC-MS methods either with PAHs or with NPAHs without requiring a major change of ionization technique. However, Cochran et al. found that the detection limits obtained when analyzing OPAHs with El were lower than when $\mathrm{NICI}$ was applied [61].

$\mathrm{El}, \mathrm{Cl}$ and $\mathrm{ECNI}$ sources are operated under vacuum (although the pressure in an El source is about $10^{5}$ times lower than in $\mathrm{Cl}$ sources). They correspond to classical setups of GC-MS and have been implemented for decades. On the other hand, more recently, some analytical scientists have adapted atmospheric pressure sources, generally coupled to liquid chromatography (see Section 3.1.2.), to gas chromatography. These works were reviewed by Li et al. [114].

The main example of such setups is GC-APCI-MS. It was recently applied by Lammel et al. for the determination of OPAHs and NPAHs [67]. Atmospheric Pressure Chemical Ionization (APCl) was operated under dry source conditions with nitrogen. This method enabled them to reach low limits of quantification (LOQ), even for high-molecular weight compounds, whose $\mathrm{LOQ}$ were below the $\mathrm{pg} \cdot \mathrm{m}^{-3}$ level in the particulate phase and in the gas phase.

Even more sensitive and selective for PAHs, Atmospheric Pressure Laser lonization (APLI) has been presented in hyphenation with GC by Schiewek et al. and Große Brinkhaus et al. 
$[115,116]$. This source is far less common than APCI, it was first presented by Constapel et al. in hyphenation with LC [117]. APLI is particularly adapted to non-polar and HMW molecules containing aromatic systems. Therefore, Schiewek et al. applied successfully GCAPLI-MS to PAHs and AZAs, Große-Brinkhaus et al. to PAHs and PASHs [115,116]. However, this source is particularly specific to PAHs and not to a lot of other compounds, thus the lack of commercial availability. In the above-quoted works, GC-APLI-MS systems where "homemade" starting from commercial APCI designs. As well as GC-APCI-MS, these systems require an additional nitrogen flow to work similarly to a LC sprayer and match the pumping speed of the MS. More details about this ionization source are presented in Section 3.1.2. In their work, Schiewek et al. compared sensitivities obtained with APLI and El. The result was outstanding: with GC-APLI-TOF-MS, they reported a sensitivity $10^{3}$ times superior to classical GC-EI-TOF-MS [116]. With a concomitant enhancement of the sensitivity and reduction of background noise because of the selectivity of APLI towards PAHs, Große Brinkhaus et al. highlighted the possibility of a higher dilution of samples to reduce degradation of the chromatographic system. The concentrations that they measured in coal and suspended PM samples were consistent with GC-EI-MS results [115].

When simple "1D" MS is performed, Single lon Monitoring (SIM) mode (or equivalents such as Single lon Storage (SIS) in lon Traps) is used for the analytes detection. It enables to "focus" the detection on only one compound with its characteristic ion, therefore increasing sensitivity and selectivity, but Andersson et al. warned against the inability of SIM mode to distinguish between co-eluting isomers, which is likely for PASHs for instance, or for PAHs pairs such as chrysene/triphenylene or benzofluoranthenes [82].

The monitored ions depend on the nature of the source, which determines if fragmentation takes place, if the molecular ion is ionized by charge transfer, by protonation or deprotonation, etc. A summary of characteristic ions for various PAC categories, various ion

Quadrupole (Q), ion trap (IT), and increasingly time-of-flight (TOF) are the most frequent GCMS analyzers. The capabilities of the analyzer also has an influence on the performance of the analytical method. For instance, in their review of GC-MS methods for PAHs determination, Poster et al. stated that the implementation of an ion trap increased selectivity compared to a quadrupole, and that with an IT, the Full Scan (FS) mode could be used instead of SIM without losing sensitivity. On the other hand, linearity issues can arise with ion traps [42]. 
The implementation of TOF analyzers seems to be promising, since TOF associates a full spectral sensitivity with a high resolving power, increasing signal-to-noise $(S / N)$ ratios [42], and presents a very high acquisition rate, enabling to distinguish peaks which could not be totally resolved by GC thanks to very low cycle times in the MS [113].

\subsubsection{LC-MS}

LC-MS hyphenations have been developed for decades with the implementation of Atmospheric Pressure Ionization (API) methods, comprising Electrospray Ionization (ESI) and Atmospheric Pressure Chemical Ionization (APCI), the two major sources used in LCMS. These are particularly suitable for polar compounds, capable of undergoing acid-base ionization reactions. However, to analyze non-polar, aprotic species, some alternatives are to be studied $[117,118]$.

Among those alternatives, Atmospheric Pressure Photoionization (APPI) is the most developed. It is based on a single-photon ionization process [114,117].

The main issue with APPI when coupled to LC is the multitude of reactions (such as clustering) due to the mobile phase. Combined to a limited photon flux, it reduces the total ion yield, especially for the molecular ion.

Dopant Assisted APPI (DA-APPI) has been developed to enhance the ionization thanks to a photoionizable compound (e.g. acetone or toluene) which can become a reactant to ionize analytes by charge exchange or proton transfer, similarly to $\mathrm{Cl}$. Nonetheless, the formation of adducts complicates the mass spectra interpretation [114,117].

To overcome the drawbacks of APPI and DA-APPI, Constapel et al. developed a novel source in 2005 : APLI [117]. With the use of a near-UV $(\lambda=248 \mathrm{~nm})$ laser beam, APLI relies on resonantly-enhanced multi-photon ionization (REMPI). As its ionization reactions are specific to PAHs and similar molecules, it disables adsorption of photons and energy transfer steps from the LC mobile phase. The resonant enhancement of the ionization process leads to a great sensitivity for PACs and for PAHs in particular.

The choice of the appropriate source is essential to yield an ionization as complete as possible. In the following paragraphs, we review studies where comparisons of the efficiency of different sources for LC-MS analysis of PACs were performed.

To our knowledge, the only successful application of LC-MS for determination of PAHs in environmental samples was obtained with APLI, because their non-polar character prevents 
an efficient ionization with the most classical commercially available API sources, i.e. ESI and APCI. LC separation of PAHs is preferentially followed by fluorescence detection (see Section 3.2.2.).

LC-APLI-TOF-MS determination of PAHs was first developed by Constapel et al [117]. The authors obtained LOD at least two orders of magnitude lower than LOD from LC-APCI-TOFMS [117]. More recently, Thiäner et al. applied this method to analyze PAHs with a particular focus on HMW PAHs (from 6 to 8 rings), which are difficult to analyze by GC-MS because of their low volatility, and reached excellent instrumental detection limits, from $0.008 \mathrm{pg}$ to 1.842 pg [119]. The main problem remaining with APLI is its lack of commercial availability.

OPAHs are slightly more polar than PAHs, thus it is possible to detect them with more familiar sources, i.e. ESI, APCI and APPI. Comparative studies of these sources were performed by Grosse and Letzel and Delhomme et al. [92,96]. Their conclusions were broadly consistent, as both articles reported that ESI was ineffective for OPAHs ionization. In contrast, APCI enables a good formation of both positive and negative ions. This duality is important because among OPAHs, great differences are observed: hydroxy-PAHs are only detected in negative mode, whereas ketones and lactones are only detected in positive mode. APPI can also be implemented for OPAHs ionization thanks to its ability to form negative ions, but APCI is preferable for its more efficient ionization in positive mode [96].

While De Guidi et al. reported the use of ESI for NPAHs analysis, Schauer et al. used APCI in both positive and negative modes [89,98]. LOD obtained by Schauer et al. were higher than LOD of LC-FD methods for NPAHs, but mass spectrometry enables a supplemental distinction of signals and the identification of compounds [98].

Lastly, azaarenes analysis by LC-MS has been described by Lintelmann et al. with the use of an APPI source in positive mode [100]. More precisely, in this work, DA-APPI was performed

In order to present a comprehensive information in our review, the major ions obtained for each PAC category with its corresponding source are reported in Table 1. Furthermore, in Table S.1., we review the important API source setups optimized in various studies to enhance the detection of PACs by LC-MS.

Table 1: Major ions monitored in MS methods for the determination of PACs 


\begin{tabular}{|c|c|c|c|c|c|c|}
\hline & & PAHs & OPAHs & NPAHs & AZAs & PASHs \\
\hline & El & $\begin{array}{l}\mathrm{M}^{+} \\
{[\mathrm{M}-\mathrm{H}]^{+}} \\
{[\mathrm{M}-2 \mathrm{H}]^{+}} \\
{[\mathrm{M}+\mathrm{H}]^{+}}\end{array}$ & 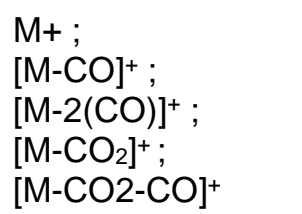 & $\begin{array}{l}\mathrm{M}^{+} \\
{[\mathrm{M}-\mathrm{NO}]^{+}}\end{array}$ & $\begin{array}{l}\mathrm{M}^{+} ; \\
{[\mathrm{M}-\mathrm{CHN}]^{+} ;} \\
{\left[\mathrm{M}-\mathrm{CH}_{2} \mathrm{~N}\right]^{+} ;} \\
{\left[\mathrm{M}-\left(\mathrm{CH}_{2}\right)_{2} \mathrm{~N}\right]^{+}}\end{array}$ & $\begin{array}{l}\mathrm{M}^{+} \\
\mathrm{M}^{2+} ; \\
{[\mathrm{M}-\mathrm{H}]^{+}} \\
{\left[\mathrm{M}-\mathrm{CS}-\mathrm{H}_{2}\right]^{+}}\end{array}$ \\
\hline & $\mathrm{NICl}$ & 1 & $\mathrm{M}^{-}$ & $\begin{array}{l}M^{-} \\
{[\mathrm{M}+\mathrm{H}]^{-}}\end{array}$ & 1 & 1 \\
\hline & $\begin{array}{l}\mathrm{APCl} \\
+\end{array}$ & I & $\begin{array}{l}\mathrm{M}^{+} \\
{[\mathrm{M}+\mathrm{H}]^{+}}\end{array}$ & $\begin{array}{l}{[\mathrm{M}+\mathrm{H}]^{+} ;} \\
{[\mathrm{M}+\mathrm{H}-\mathrm{OH}]^{+} ;} \\
{[\mathrm{M}+\mathrm{H}-\mathrm{NO}]^{+} ;} \\
{[\mathrm{M}+\mathrm{H}-\mathrm{HNO}]_{2}^{+} ;}\end{array}$ & I & l \\
\hline \multirow[t]{4}{*}{$\mathrm{MS}^{1}$} & $\begin{array}{l}\mathrm{APCl} \\
-\end{array}$ & I & $\begin{array}{l}M^{-} \\
{[\mathrm{M}-\mathrm{H}]^{-}}\end{array}$ & $\begin{array}{l}\mathrm{M}^{-} \\
\left.\mathrm{M}^{-} \mathrm{NO}\right]^{-}\end{array}$ & l & l \\
\hline & $\begin{array}{l}\text { APPI } \\
+\end{array}$ & l & $\begin{array}{l}\mathrm{M}^{+} \\
{[\mathrm{M}+\mathrm{H}]^{+}}\end{array}$ & I & {$[\mathrm{M}+\mathrm{H}]^{+}$} & l \\
\hline & APPI & l & $\begin{array}{l}\mathrm{M}^{-} \\
{[\mathrm{M}-\mathrm{H}]^{-}}\end{array}$ & l & l & l \\
\hline & APLI & $\mathrm{M}^{+}$ & I & l & $\mathrm{M}^{+}$ & $\mathrm{M}^{+}$ \\
\hline $\mathrm{MS}^{2}$ & CID & $\begin{array}{l}-\mathrm{H}(-1) ; \\
-\mathrm{H}_{2}(-2) ; \\
-\mathrm{C}_{2} \mathrm{H}_{2}(-26) ; \\
-\mathrm{C}_{4} \mathrm{H}_{2}(-50)\end{array}$ & $\begin{array}{l}-\mathrm{CO}(-28) ; \\
-(\mathrm{CO}+\mathrm{H})(-29) ; \\
-(\mathrm{CO}+\mathrm{H})(-45) ; \\
-2(\mathrm{CO})(-56) ; \\
-(2(\mathrm{CO})+\mathrm{H})(-57)\end{array}$ & $\begin{array}{l}-\mathrm{C}_{2} \mathrm{H}_{2}(-26) ; \\
-\mathrm{NO}(-30) \\
-\mathrm{NO}_{2}(-46)\end{array}$ & $\begin{array}{l}-\mathrm{CH}_{2} \mathrm{~N}(-28) ; \\
-\mathrm{C}_{2} \mathrm{H}_{5} \mathrm{~N}(-33) ; \\
-\mathrm{C}_{4} \mathrm{H}_{5}(-53)\end{array}$ & $\begin{array}{l}-\mathrm{C}_{2} \mathrm{H}_{2}(-26) ; \\
-\mathrm{CS}(-44) ; \\
-\mathrm{CSH}(-45)\end{array}$ \\
\hline Refs & & $\begin{array}{l}{[19,34,54,79,109,11} \\
7,120]\end{array}$ & $\begin{array}{l}{[17,19,31,92,94,9} \\
6,121]\end{array}$ & {$[19,36,98,102,110]$} & {$[74,100,116]$} & {$[78,115,122]$} \\
\hline 746 & \multicolumn{6}{|c|}{ * In Table 1, alkylated PACs are not taken into account. In the case of the MS detection of these } \\
\hline 747 & \multirow{2}{*}{\multicolumn{6}{|c|}{$\begin{array}{l}\text { compounds, the loss of the alkyl substitutes }\left(\mathrm{CH}_{3}, \mathrm{C}_{2} \mathrm{H}_{5} \text {, etc ...) gives birth to the major fragments, }\right. \\
\text { either in-source or collision-induced. }\end{array}$}} \\
\hline 748 & & & & & & \\
\hline
\end{tabular}

749

750

3.1.3. Tandem Mass Spectrometry (MS/MS)

751

752 As discussed in Section 3.1.1, SIM mode can be problematic for isomers, which are frequent

753 in PACs analyses. In fact, Antle et al. reported that between 1995 and 2014, up to $75 \%$ of

754 analytical studies on PAHs and PASHs using GC-MS in SIM mode with the detection of one

755 ion only resulted to incorrect peak assignments and false positives [80].

756 To monitor multiple ions simultaneously for each analyte is a possible solution, but it

757 sometimes does not eliminate all the possible confusions, because some isomers have a

758 very similar structure and therefore exhibit the same fragmentation patterns in the source.

759

760 Tandem Mass Spectrometry (MS/MS or $\mathrm{MS}^{2}$ ) has been applied successfully to PAHs

$761[34,54,102,109,112]$, OPAHs [67,71,92,94,102,112], NPAHs [36,67,71,102,112], AZAs [100]

762 and PASHs [122]. This technique offers more specificity than MS ${ }^{1}$. 
For PACs detection after chromatographic separation, MS/MS is often performed with a triple quadrupole used in Multiple Reaction Monitoring (MRM) mode. MRM generally takes profit of Collision Induced Dissociation (CID) processes. Depending on the stability of the ion, collision energies from 5 to $50 \mathrm{eV}$ have to be applied in the collision cell to perform fragmentation.

While compounds of the same molecular mass exhibit disturbing signals in SIM mode (either noise at different retention times or interferences at the same retention time), these signals will be reduced with the use of MRM mode. Thus, $\mathrm{S} / \mathrm{N}$ are generally increased and detection limits reduced with the use of MS/MS.

As stated above, a large majority of Tandem Mass Spectrometers are Triple Quadrupole (QQQ) devices. The use of Quadrupole - Time-Of-Flight (Q-TOF) instruments is increasing because of the enhancement of sensitivity and resolving power and the reduction of cycle time brought by the TOF analyzer (see Section 3.1.1.). Ion Trap also offers the possibility of performing MS/MS in a sole analyzer thanks to the application of collision energies inside the IT.

For what regards PACs, fragmentation patterns found in MS/MS experiments are given in Table 1, with the functional groups cleaved by CID and their associated mass losses.

Among PACs, one group is particularly resistant to CID: parent PAHs. They are only constituted of aromatic rings, do not comprise any heteroatom or alkyl group. Therefore, their structure is very stable, even when CID is applied. This phenomenon complicates their analysis in MRM mode. This is why Lian et al. implemented a "pseudo-MRM" method [34]. This means that the monitoring of the intact molecular ion selected in the first analyzer was also performed in the second analyzer. No fragmentation was targeted in the collision cell, even if mild energies were still applied. Transitions with non-zero mass losses, which give a less intense signal in the case of PAHs, were only used as confirmation. It is worth noting that these transitions corresponded to very small mass losses (mainly the elimination of one or two hydrogen atoms, more rarely of a $\mathrm{C}_{2} \mathrm{H}_{2}$ moiety) [34].

Villanueva et al. chose to apply "classical" MRM instead of pseudo-MRM for their analysis of PAHs, but they had to apply high CEs (from 18 to $40 \mathrm{eV}$ for LMW PAHs and from 30 to 40 $\mathrm{eV}$ for HMW PAHs) to obtain fragments from CID [109]. The predominance of $\mathrm{H}$ and $\mathrm{C}_{2} \mathrm{H}_{2}$ knockouts was also observed and is explained in the work of Stockett et al. [120].

\subsection{Other detectors}


802 Even though MS has become extensive in the field of environmental analysis, other

803

804

805

806

807

808

809

810

811

812

813

814

815

816

817

818

819

820

821

822

823

824

825

826

827

828

829

830

831

832

833

834

835 possibilities exist to detect PACs after a chromatographic separation.

They usually offer less sensitivity and do not enable an identification of unknown compounds as MS does.

Still, it can be interesting to implement them on economic grounds or because of their ease of use. In the subsections below, these alternatives to MS and some of their operating parameters are detailed.

\subsubsection{After GC separation}

The traditional detector for GC determination of organic molecules is the Flame Ionization Detector (FID). Only carbon-based molecules can be detected by FID, and their response is approximately proportional to the amount of carbon atoms, which is interesting for PACs and more particularly for PAHs detection [40,42,123]. However, a major inconvenient of FID is that all organic molecules give responses. This is problematic for complex matrices such as atmospheric PM or diesel particulates for instance. These kinds of samples would therefore require a very intensive clean-up before analysis, so that aliphatic compounds and lipids for example can be removed [124].

Moreover, Cox and Earp have reported a better sensitivity of PAHs determination with a Photoionization Detector (PID) [123]. It is appropriate for volatile and semi-volatile organic compounds whose ionization energy is lower than the energy of emitted photons (from 8 to $12 \mathrm{eV}$ ). Its use for PAHs analysis has also been reported by Poster et al. [124].

A wider variety of detectors is available for polar PACs, especially NPAHs. Indeed, for nitrogen-containing analytes, the use of a nitrogen-phosphorus detector (NPD) can be interesting. This detector works with a flame ionization, similarly to FID, but redox reactions take place selectively with $\mathrm{N}$ or $\mathrm{P}$ atoms. Therefore, NPD has been broadly applied for NPAHs and AZAs determination [24,40,107].

The Electron Capture Detector (ECD) is specific to electronegative molecules, which is why it has been used for NPAHs and OPAHs detection [13,24,70].

For PASHs analysis, the preferred detector is the Atomic Emission Detector (AED).

Wavelengths specific to single atoms can be monitored, and AED proved itself particularly efficient for PASHs determination when both carbon $(\lambda=193 \mathrm{~nm})$ and sulfur $(\lambda=181 \mathrm{~nm})$ 
selective modes were applied $[29,81,82]$. The simultaneous recording of carbon emission enables to check the presence of a PASH responsible for the sulfur signal, because otherwise, false positives can occur because of non-sulfur compounds present in high concentrations which may create interferences [82].

\subsubsection{After LC separation}

Like GC, LC can be followed by a selective detector other than MS. To our knowledge, three different kinds of detectors have been implemented for PACs detection after LC separation: ultraviolet (UV), fluorescence (FLD) and chemiluminescence (CLD) detectors.

In the general rule, UV detection is the method of the choice after LC separation. It was applied by Dong and Lee for the determination of PAHs $(\lambda=260 \mathrm{~nm})$ and by Wilson et al. for the determination of PASHs $(\lambda=254 \mathrm{~nm} ; 294 \mathrm{~nm} ; 313 \mathrm{~nm})[101,125]$. However, the vast majority of PAHs and derivatives exhibit fluorescence, therefore this latter is preferred because it increases significantly the selectivity and the sensitivity compared to UV $[124,126]$. Among PAHs, acenaphthylene is the only non-fluorescent molecule, and it is therefore the only one detected by UV in LC analysis methods of PAHs $[86,87]$.

OPAHs and NPAHs are the exceptions to the fluorescence properties of PACs. Indeed, these compounds are not fluorescent and require reduction, either before their LC separation or after it.

Barrado-Olmedo et al. implemented an off-line reduction of NPAHs to amino-PAHs (APAHs) with $\mathrm{NaBH}_{4}$ and $\mathrm{CuCl}_{2}$, but the additional time required for such derivatization methods is a major drawback when large sample sets have to be analyzed [24,90]. According to Delhomme et al., if the reduction column is positioned before the separation column, one obtains a decrease in peak areas and a higher variability of retention times. Moreover, the simultaneous injection of all OPAHs and NPAHs of the sample on the reduction column saturates the latter much sooner than if individual PACs reach the reduction column separately [99]. Therefore, on-line post-column reduction of OPAHs and NPAHs is generally favored $[92,98,99]$. This way, they are reduced to hydroxy-PAHs and amino-PAHs, respectively. A $50 \mathrm{~mm}$ long column filled with a $\mathrm{Pt}$ catalyst on a $\mathrm{y}-\mathrm{Al}_{2} \mathrm{O}_{3}$ support is ideal for the conversion of NPAHs into amino-PAHs $[98,99]$.

Excitation and emission wavelengths stated in works using LC-UV and LC-FLD for the determination of PACs are transcribed in Table S.2. 
875 Finally, chemiluminescence detection (CLD) has been used many times for the analysis of

876 NPAHs following the same initial method $[17,83,97]$. Similarly to FLD, it requires a prior

877 derivatization of NPAHs, because chemiluminescence is more intense with amino-PAHs. In

878 the method developed by Hayakawa et al., the mobile phase in the separation column is

879 composed of acetonitrile and an aqueous solution of imidazole and perchloric acid buffer at

$880 \mathrm{pH}$ 7.6. Then, the post-column chemiluminescence reagent solution is composed of

881 bis(2,4,6-trichlorophenyl)oxalate (TCPO) and hydrogen peroxide. The amino-PAHs thus

882 formed are in an excited state thanks to energy transfer from the simultaneous dissociation

883 of TCPO, and exhibit chemiluminescence responsible for their detection [97]. This process

884 and its application to LC-CLD determination of NPAHs was described in detail by Hayakawa

885 [127].

886 The sensitivity of CLD has been reported as close to or higher than the sensitivity of FLD for

887 NPAHs [24,127].

888 To our knowledge, among PACs, only NPAHs have been extensively analyzed thanks to

889 chemiluminescence detection.

890

891 To conclude this section, we would like to highlight that we have presented several different

892 detectors which are each intended for a special class of PACs. Therefore, it is not possible to

893 obtain a sensitive detection of all PACs categories reviewed here in a unique

894 chromatography run if MS is not the detection method.

895 
897

898

899

900

901

902

903

904

905

906

907

908

909

910

911

912

913

914

915

916

917

918

919

920

921

922

923

924

925

926

927

928

929

930

931

\subsection{PAHs}

Among PACs, PAHs are by far the most extensively studied compounds. They have been measured in airborne particulate matter and dusts of indoor and outdoor environments in the last decades.

The main issue when one wants to compare PAHs levels reported in different studies is that such levels are generally summarized in the form of a sum of all analyzed PAHs ( $\mathrm{PPAHs}$ ), but the total number of analyzed PAHs can significantly vary. Indeed, while occurrence studies have long been based on the list of EPA's 16 priority PAHs, it has recently been highlighted that this list is relatively flawed and that some PAHs outside this list are worthy of a more extensive analytical evaluation [12]. This explains why some lists of target compounds have been opened up to more than sixteen, whereas others are reduced due to analytical constraints such as standards availability or robustness of the method.

Therefore, in the sum-up tables reported in the Supplement of this article (Table S.3.), we will report mean concentrations of all measured PAHs (total PAHs concentration stated in each study divided by the number of PAHs individual compounds).

In settled dust, PAHs concentrations are below or around the sub- $\mu \mathrm{g} \cdot \mathrm{g}^{-1}$ range (see Table S.3.C.) $[4,39,128]$.

In atmospheric PM, PAHs are commonly found at the $\mathrm{ng} \cdot \mathrm{m}^{-3}$ level. According to the work of Cave et al. who informatically reviewed about 3000 papers dealing with $\mathrm{PAHs}$ in particulate samples, most of concentrations given in abstracts where between 0 and $10 \mathrm{ng} \cdot \mathrm{m}^{-3}$ but some outlier data points where in the range $500-2000 \mathrm{ng} \cdot \mathrm{m}^{-3}$ [129]. This conclusion is illustrated by Figure 2, presenting the range of data reported in papers where the most frequently used unit was $\mathrm{ng} \cdot \mathrm{m}^{-3}$. However, the role of this figure is limited to providing a broad overview of PAHs occurrence values. Cave et al. cannot be sure that each of these data points refer to $\mathrm{PAH}$ concentrations and, if they do, which PAH compound it refers to. Still, the overall distribution trend of PAHs concentrations inside the $\mathrm{ng} \cdot \mathrm{m}^{-3}$ order of magnitude is interesting to notice.

Among recent works, whereas concentrations in the order of $0.1 \mathrm{ng} \cdot \mathrm{m}^{-3}$ have been measured in southern Europe $[35,56,108]$ and Chile [58], levels of several $\mathrm{ng} \cdot \mathrm{m}^{-3}$ have been obtained in China [68,130-132] and Afghanistan [133]. Hypotheses concerning the regulations of each 
country on major PAHs sources such as industrial activities, vehicular emissions from traffic and domestic heating can explain these differences.

In addition to international differences regarding PAHs levels, it is also interesting to take a closer look on local variations between sampling locations from the same study. In particular, major differences can be obtained between samples from remote areas and samples collected in urban environments, close to PAHs main sources.

For instance, Schauer et al. reported a tenfold increase in PAHs concentration in an urban area of Munich compared to rural and mountainous environments of the same region [98]. In Chile, Scipioni et al. measured a PAHs concentration about 18 times higher in the urban site of Concepcion than in the remote site of Coyhaique [58].

Other trends to be studied are seasonal variations. As a general rule, PAHs levels are lower in summer than in winter, mainly because of the reduced emissions due to residential heating, and also due to a higher atmospheric degradation of PAHs into derivatives with the increase of temperature and sunlight. These hypotheses are coherent with results in Table S.3. $[68,89,108]$.

Nonetheless, Kim et al. reported that indoor sources of pollution in indoor public facilities affect more PAHs levels than seasonal trends [134], consistently with the conclusions of Delgado-Saborit et al. who reported a possible prevalence of indoor sources (tobacco smoke, wood burning, heating, cooking, ...) over outdoor infiltration of PAHs [135].

When comparing indoor environments of urban and rural areas, Liaud et al., as well as Anh et al., observed higher PAH levels in rural houses, contradictory to common PAH trends in outdoor environments, with a possible higher contribution of coal and biomass combustion for heating and cooking $[55,136]$.

Among indoor sources, cigarette smoke seems to be the most crucial one. Indeed, in the study of Delgado-Saborit et al., the highest PAHs concentrations were measured in airborne particulates from pubs where Environmental Tobacco Smoke (ETS) was present [135] and in the study of Castro et al., PAHs levels in $\mathrm{PM}_{10}$ and $\mathrm{PM}_{2.5}$ were twice higher in smoker homes than in non-smoker homes [86]. In the United States, Hoh et al. also established the correlation between ETS and PAHs in settled house dust (SHD) [137]. In a previous study, Mitra and Ray identified ETS as the most significant indoor PAHs source, contributing to almost $87 \%$ of the PAHs measured in air of smokers' homes [3].

As suggested by the very high levels of PAHs measured by Li et al. in PM 2.5 close to cooking sources which were up to 36 times higher than the associated background levels, 
cooking activities, and particularly roasting and frying, are also major PAH sources in indoor environments [9].

Methods used to assess the source apportionment of PAHs have been reviewed by Tobiszewki and Namieśnik [10].

First, the predominance of high molecular weight (HMW) over low molecular weight (LMW) PAHs indicates an origin from high temperature combustion processes (e.g. fuels in engines), while the opposite rather suggests a major contribution of low temperature combustions (e.g. wood burning) [10].

Then, it is common that ratios of pairs of PAHs which have the same molecular weight are calculated to assess the preponderance of particular sources. In that respect, ratios of isomers such as indeno[1,2,3-cd]pyrene / (indeno[1,2,3-cd]pyrene + benzo[ghi]perylene), fluoranthene / (fluoranthene+pyrene) or benz(a)anthracene / (benz(a)anthracene+chrysene) for instance can characterize the carburant responsible for PAHs emission (petrol, diesel, coal, wood, ...) [6,8-10,75].

Moreover, the concentrations of several individual PAHs are handled because they give special information: for example, chrysene can be used to estimate infiltration ratios between indoor and outdoor air because its only possible source in indoor environments is cigarette smoke [7], and retene is characteristic of cellulose burning [138], even if Alves et al. have reported its occurrence in an urban road tunnel, suggesting that vehicular exhausts are probably another source of retene emission and that its use as a wood combustion tracer should be performed with great caution [75].

The main drawback of these approaches is the atmospheric reactivity of PAHs which disables a certain identification of the source of a PAH mixture, because if they have been emitted long ago, and that their decay rate constants are different, their ratio is not conservative over time. Furthermore, other biases such as gas/particle partitioning or seasonal variations can affect these ratios [10].

A possible improvement to decrease the uncertainty related to these diagnostic ratios is the use of cross-plots of two diagnostic ratios versus each other [48,57,75,130].

For the purpose of a more accurate source attribution of PAHs, other research groups have oriented their efforts towards source apportionment based on different methods involving molecular markers outside the PAH category [139], and statistical methods such as Cluster Analysis (CA) and Principal Component Analysis (PCA) have also been implemented [140].

Besides the mean PAH concentration, we report in Table S.3. the most concentrated PAH measured, to give an additional overview of the most important compounds to include in risk 
assessment studies. These major PAHs are, in most environmental samples, compounds from the list of 16 priority PAHs, with the exception of benzo(e)pyrene in the studies of Di Filippo et al., Kim et al. and Li et al., and retene in the study of Alves et al $[9,108,134,141]$. Methylated PAHs such as 2,6-dimethylnaphthalene and 1-methylpyrene have also been found preponderant in combustion exhausts and soots [102,142].

However, we want to highlight that the sole concentration of a PAH in a sample does not account for the real hazard related to it. Indeed, PAHs toxicities vary significantly inside the group. The most widely used method to assess the toxicity of a sample containing PAH is to use the Toxic Equivalency Factor with respect to $B[a] P(T E F=1)$. The work taken as reference in most cases for the use of TEFs is the one of Nisbet and LaGoy, where TEFs are attributed to the 16 EPA's priority PAHs. They range between 0.001 and 5 [143]. This explains why dibenz[a,h]anthracene $(\mathrm{DB}[\mathrm{a}, \mathrm{h}] \mathrm{A})$, the only PAH to be associated to a TEF superior to $\mathrm{B}[\mathrm{a}] \mathrm{P}$, frequently accounts the most for the global toxicity of a PM sample while it is often one of the less concentrated compounds. Furthermore, in their study, Collins et al. added the dibenzopyrene isomers, which are 6-rings PAHs known for their acute toxicity and possible carcinogenicity, and reported PEFs from 1 to 10 for these compounds [26]. Similarly to $\mathrm{DB}[\mathrm{a}, \mathrm{h}] \mathrm{A}$, these HMW PAHs, because of their known toxicological properties, should be included in environmental analyses of PAHs.

\subsection{OPAHs}

Interests in OPAHs have been lower than those in PAHs up to now, but they have been measured in outdoor atmospheric PM around the world.

On the other hand, only Du et al. measured OPAHs in indoor PM, reporting a higher concentration than in their associated outdoor measurements [111]. Therefore, analysis of OPAHs in indoor environments is a critical lack in the current knowledge of the occurrence of these compounds. Moreover, no data on OPAHs concentrations in settled dusts have been published, and only two articles report OPAHs concentrations in combustion exhausts particulates [61,102].

For what regards outdoor levels of OPAHs in atmospheric PM, Walgraeve et al. pooled a lot of results and concluded that for individual oxy-PAHs, $50 \%$ of the reported concentrations were between 0.080 and $0.960 \mathrm{ng} \cdot \mathrm{m}^{-3}$ (median: $0.270 \mathrm{ng} \cdot \mathrm{m}^{-3} ; \mathrm{n}=689$ ), whereas for individual hydroxylated PAHs, $50 \%$ of the reported concentrations were between $0.013 \mathrm{ng} \cdot \mathrm{m}$ ${ }^{3}$ and $14.1 \mathrm{ng} \cdot \mathrm{m}^{-3}$ (median: $0.090 \mathrm{ng} \cdot \mathrm{m}^{-3} ; \mathrm{n}=31$ ) [15]. 
In terms of geographical variations, while mean concentrations of OPAHs in airborne PM reported in France and Germany for instance were around or below $0.1 \mathrm{ng} \cdot \mathrm{m}^{-3}[23,37,64,88]$, they reached from 1 to $10 \mathrm{ng} \cdot \mathrm{m}^{-3}$ in China and Afghanistan $[111,131,133]$. These results are gathered in Table S.4.

Local trends of OPAHs follow those of PAHs: rural and remote areas are in the general rule less affected by OPAHs pollution, as shown by the study led in Czech Republic by Lammel et al. who compared samples from the rural town of Kosetice with samples from Kladno, where important industrial activities are located, and Ostrava, one of the biggest Czech cities with an important industrial activity as well. OPAHs levels in PM were far lower in Kosetice [67]. Similarly, Ringuet et al. reported a 15-fold increase between OPAHs levels in PM of a suburban site in the region of Paris and those of an urban traffic site [23].

The results of many studies match to confirm the seasonal pattern described in Section 4.1: ambient concentrations of PACs are higher in winter than in summer $[67,68,88,108]$. First, ambient conditions in winter favor the enrichment of PACs in PM. Furthermore, for OPAHs, this seasonal difference highlights an important observation: higher concentrations in winter imply a predominance of primary emissions of these compounds over secondary formation from atmospheric degradation of $\mathrm{PAHs}$, which would be their main origin in summer $[15,19]$.

Such conclusions can be confirmed or rejected by the study of some diagnostic ratios, namely the ratio of OPAHs over their corresponding "parent" $\mathrm{PAH}$, such as 9fluorenone/fluorene or 9,10-anthraquinone/anthracene for instance [131,133]. According to the review of Walgraeve et al., one can expect to find these ratios around 0.1 in winter, and about 20 times higher in summer, when secondary formation of OPAHs due to photochemical activity is the highest [15]. These ratios can also be complemented by the ratio of benzo(e)pyrene over benzo(a)pyrene, which is around 1 close to emission sources, and increases with photochemical aging of PAHs, to which benzo(a)pyrene is particularly sensitive [131].

\subsection{NPAHs}

In Table S.5. are reviewed reported levels of NPAHs in airborne PM and in combustion exhausts particulates.

In general, NPAHs levels are lower than PAHs and OPAHs. One exception is the "outlier" study of Keyte et al. in which reported NPAHs concentrations were up to $287 \mathrm{ng} \cdot \mathrm{m}^{-3}$, which is 
1078 huge but partly explicable by the sampling place, a road tunnel with heavy traffic in Paris 1079 [37].

1080 Otherwise, typical levels of NPAHs in airborne PM are typically in the $\mathrm{pg} \cdot \mathrm{m}^{-3} \mathrm{range}$

1081

1082

1083

1084

1085

1086

1087

1088

1089

1090

1091

1092

1093

1094

1095

1096

1097

1098

1099

1100

1101

1102

1103

1104

1105

1106

1107

1108

1109

1110

1111

1112

1113

1114

$[23,64,71,88,99]$, occasionally closer to the $\mathrm{ng} \cdot \mathrm{m}^{-3}$ level $[108,111,131]$. In remote or rural areas where few sources of PACs are found, mean levels of the measured NPAHs can even be below the $\mathrm{pg} \cdot \mathrm{m}^{-3}$ threshold $[58,67,98]$.

Nevertheless, toxicological properties of a lot of NPAHs are stronger than those of PAHs for instance, particularly in terms of mutagenicity and carcinogenicity. Indeed, their mutagenicity has been confirmed, some PEFs higher than those of PAHs have been attributed to NPAHs and several NPAHs are classified as probable or possible carcinogens [13,26].

This is why even at such low concentrations, NPAHs need to be analyzed in atmospheric PM, but also in PM and settled dusts of indoor environments, which has not been the case up to now, except for the study of Du et al. where NPAHs levels were higher indoors than outdoors, a result increasing the interests in such environments, as well as for OPAHs [111].

Winter concentrations of NPAHs in airborne PM are clearly above summer concentrations $[67,99,108]$. This observation results from a combination of meteorological parameters (inversion temperature layers for instance), increased emissions, and gas/particle partitioning (higher proportion of NPAHs in the gas phase in summer).

In NPAHs assessment studies, particular interests are drawn in the nature of their source, mainly primary versus secondary formation. For this purpose, one can focus on the 2nitrofluoranthene to 1-nitropyrene ratio which gives information about the predominance of primary or secondary sources, and on the 2-nitrofluoranthene to 2-nitropyrene ratio which tells if secondary formations of polar PACs are mainly $\mathrm{OH}$-initiated or $\mathrm{NO}_{3}$-initiated $[13,19$ $21,23,24,71]$. Similarly to OPAHs, it can also be interesting to study the ratio of NPAHs to their parent PAHs to get information about the atmospheric degradation of PAHs into NPAHs $[108,131]$.

Moreover, for apportionment between sources of airborne NPAHs, Ma et al. used PMF and Beta statistical methods, and Lin et al. developed a statistical approach based on the correlation coefficient between log-transformed NPAHs and $\mathrm{NO}_{2}$ concentrations $[20,144]$. 
AZAs have been less determined in environmental samples than the previously introduced PACs. Nonetheless, their occurrence has been shown in several studies. Because of the small amount of such studies, a major challenge for their comparison is the variability of the target molecules. Indeed, while Alves et al., Bandowe et al. and Wei et al. only measured three to four AZAs, Chen and Preston performed a more comprehensive work on 47 AZAs, without being able to identify precisely each isomer (which is why they gathered compounds in groups of isomers) and Delhomme and Millet analyzed 20 AZAs, reporting "group" concentrations depending on the molecules' number of rings [25,27,74,108,131,145]. Therefore, to review the results with the highest possible representativeness, we present in Table S.6 a mean concentration of azaarene individual compounds in airborne PM, either directly reported in the literature or calculated from global results. These levels are generally in the sub-ng $\cdot \mathrm{m}^{-3}$ range, close to those of OPAHs and NPAHs.

To the best of our knowledge, no result has been published regarding AZAs levels in dusts or soots, else than Sauvain et al. who measured dibenzacridine and dibenzocarbazole in outlet particulates of a diesel van, but did not detect any of these above their limit of detection (LOD) [43]. Therefore, more studies are required to assess the ubiquity of AZAs in various environments.

AZAs levels in PM increase in winter, due to more important direct emissions, a greater fraction of AZAs in the particulate phase, and less photochemical degradation among others $[25,27,145]$.

As described for other PACs, the ratio of AZAs to their related parent PAHs can be interesting for source apportionment. Indeed, AZAs are considered as typical of coal combustion and a predominance of this source can be characterized by high values of the individual AZA / related $\mathrm{PAH}$ ratio [145].

\subsection{PASHs}

PASHs is the class of PACs for which the fewest occurrence data are available for particulate matters. These compounds have mainly been determined in coal- and oil- related samples because they are characteristic of these materials [29,80-82,122]. Other samples studied are generally sediments, natural water or wastewater samples $[80,82]$.

To the best of our knowledge, the only analytical study reporting concentrations of PASHs in environmental particulate matter was conducted by Wang et al. [49]. In the total airborne PM sampled near a roadside of a national route in Japan, they measured from 0.01 to $0.03 \mathrm{ng} \cdot \mathrm{m}$ ${ }^{3}$ of three PASHs: dibenzothiophene, benzo[b]naphtho[1,2-d]thiophene and 
1152 benzo[b]naphtho[2,1-d]thiophene. These concentrations are lower than the vast majority of

1153 PAHs which were determined simultaneously. Of course, this sole result is not sufficient to

1154 characterize the atmospheric pollution caused by PASHs, indoors as well as outdoors, and

1155 we encourage analysts willing to study PACs in environmental particulate matters in the

1156 future to include PASHs in their projects.

1157

1158 Vu-Duc et al. analyzed 37 PAHs and 5 PASHs in the aerosol of laboratory generated

1159 bitumen fumes [79]. They obtained relatively high levels of dibenzothiophene (384 $\pm 38 \mu \mathrm{g} / \mathrm{g}$

1160 of fumes) and lower levels of benzonaphthothiophene isomers. In their sample, PASHs

1161 concentrations were far below those of the 9 major PAHs, but above those of 22 non-

1162 detected PAHs, emphasizing once more the need of further assessment of PASHs in the

1163 environment due to their existing emissions in various combustion processes. 
Airborne particulate matter, dust and other particulates such as soot or combustion exhaust particulate matter are major emission sources of organic pollutants, some of them exhibiting a strong toxicity.

Among these compounds raising concerns, PACs constitute an important category. This class of compounds is made up of hundreds of molecules differing in their polarity, volatility, toxicological properties, etc. Thus, their analysis in environmental studies is a major challenge. While lists of compounds of interest were too much restricted in the past, particularly due to the flawed definition of a single list of 16 compounds of interests, the EPA's 16 priority PAHs list, we propose in the present paper to enlarge the amount of PACs studied in environmental assessments, outside the subclass of non-polar PAHs.

Obviously, this goes together with an increased analytical difficulty. In the present review, we highlight the technical trends which are, in our opinion, the most promising to solve the analytical issues related to trace and ultratrace levels of a huge amount of compounds, including isomers, in complex samples. Maximizing the number of analytes gathered in a single analytical run similarly to the sensitivity of their detection is the most important challenge of future developments in the field of PACs environmental analysis. To this purpose, current instrumental limitations are expected to be reduced in the coming years. Among those improvements, the performance of the separation column in terms of number of plates, thus giving higher resolving powers and higher peak capacities, is crucial. This tendency steers the choice of the separation method to GC rather than LC because of their respective peak capacities.

However, the acquisition of a lot of very thin peaks leads to an additional issue for what regards MS detection. Indeed, it requires a very high mass spectral acquisition rate. This parameter is particularly enhanced with TOF analyzers (around $10^{3} \mathrm{~Hz}$ ), which we expect to be increasingly used in hyphenation with GC for PACs analysis. Reaching huge resolutions as it could be done with Orbitrap and FT-ICR analyzers is of no real use for PACs, whereas an optimal cycle time is crucial.

MS/MS is also necessary to obtain fragmentation patterns enabling the differentiation of isomers which are numerous among PACs. Therefore, IT and QQQ are not obsolete at all, but Q-TOF can be preferred. 
1201 Apart from the technical evolutions, the future of PACs environmental analysis resides in the 1202 adjustments of standards and in the transfer of novel methods towards routine control

1203 laboratories. A lot of assessment studies performed in such laboratories still focus on the 1204 EPA's list and on other elementary compounds. It is necessary that the forthcoming analysis 1205 methods include as many compounds as possible, and that they are then rapidly adapted to 1206 be used routinely with appropriate analytical equipment, following precise guidelines in terms 1207 of method validation and quality control among others.

1209 We reported typical levels of PACs which can vary from the sub-pg $\cdot \mathrm{m}^{-3}$ level to several $\mathrm{ng} \cdot \mathrm{m}^{-}$ $1210{ }^{3}$ in atmospheric particulate matter and in the $\mu \mathrm{g} \cdot \mathrm{g}^{-1}$ range in settled dusts and combustion 1211 exhausts particulates. These occurrence values have to be critically interpreted depending 1212 on the sampling location and time because of geographical and seasonal variations, and 1213 their health and environmental relevance is strongly related to the individual toxicity of the 1214 PACs in question. 


\section{Acknowledgements}

1217

1218 This work was supported by a Ph.D. grant from the French Ministry of Higher Education,

1219 Research and Innovation and the University of Strasbourg.

1220

1221 Appendix

1222

1223 Supplemental Content of this article can be found in the online version, at ... 


\section{References}

[1] I.J. Keyte, R.M. Harrison, G. Lammel, Chemical reactivity and long-range transport potential of polycyclic aromatic hydrocarbons - a review, Chem. Soc. Rev. 42 (2013) 9333. https://doi.org/10.1039/c3cs60147a.

[2] S. Manzetti, Polycyclic Aromatic Hydrocarbons in the Environment: Environmental Fate and Transformation, Polycyclic Aromatic Compounds. 33 (2013) 311-330. https://doi.org/10.1080/10406638.2013.781042.

[3] S. Mitra, B. Ray, Patterns and sources of polycyclic aromatic hydrocarbons and their derivatives in indoor air, Atmospheric Environment. 29 (1995) 3345-3356. https://doi.org/10.1016/13522310(95)00214-J.

[4] R.M. Maertens, J. Bailey, P.A. White, The mutagenic hazards of settled house dust: a review, Mutation Research/Reviews in Mutation Research. 567 (2004) 401-425. https://doi.org/10.1016/j.mrrev.2004.08.004.

[5] K. Slezakova, D. Castro, C. Delerue-Matos, S. Morais, M. do C. Pereira, Levels and risks of particulate-bound PAHs in indoor air influenced by tobacco smoke: a field measurement, Environ Sci Pollut Res. 21 (2014) 4492-4501. https://doi.org/10.1007/s11356-013-2391-5.

[6] K. Slezakova, D. Castro, C. Delerue-Matos, M. da C. Alvim-Ferraz, S. Morais, M. do C. Pereira, Impact of vehicular traffic emissions on particulate-bound PAHs: Levels and associated health risks, Atmospheric Research. 127 (2013) 141-147.

https://doi.org/10.1016/j.atmosres.2012.06.009.

[7] H. Choi, J. Spengler, Source attribution of personal exposure to airborne polycyclic aromatic hydrocarbon mixture using concurrent personal, indoor, and outdoor measurements, Environment International. 63 (2014) 173-181. https://doi.org/10.1016/j.envint.2013.11.007.

[8] K. Ravindra, R. Sokhi, R. Vangrieken, Atmospheric polycyclic aromatic hydrocarbons: Source attribution, emission factors and regulation, Atmospheric Environment. 42 (2008) 2895-2921. https://doi.org/10.1016/j.atmosenv.2007.12.010.

[9] Y.-C. Li, J.-Q. Qiu, M. Shu, S.S.H. Ho, J.-J. Cao, G.-H. Wang, X.-X. Wang, X.-Q. Zhao, Characteristics of polycyclic aromatic hydrocarbons in PM2.5 emitted from different cooking activities in China, Environ Sci Pollut Res. 25 (2018) 4750-4760. https://doi.org/10.1007/s11356017-0603-0.

[10] M. Tobiszewski, J. Namieśnik, PAH diagnostic ratios for the identification of pollution emission sources, Environmental Pollution. 162 (2012) 110-119. https://doi.org/10.1016/j.envpol.2011.10.025.

[11] L.H. Keith, The Source of U.S. EPA's Sixteen PAH Priority Pollutants, Polycyclic Aromatic Compounds. 35 (2015) 147-160. https://doi.org/10.1080/10406638.2014.892886.

[12] J.T. Andersson, C. Achten, Time to Say Goodbye to the 16 EPA PAHs? Toward an Up-to-Date Use of PACs for Environmental Purposes, Polycyclic Aromatic Compounds. 35 (2015) 330-354. https://doi.org/10.1080/10406638.2014.991042.

[13] B.A.M. Bandowe, H. Meusel, Nitrated polycyclic aromatic hydrocarbons (nitro-PAHs) in the environment - A review, Science of The Total Environment. 581-582 (2017) 237-257. https://doi.org/10.1016/j.scitotenv.2016.12.115.

[14] G. Lammel, Polycyclic Aromatic Compounds in the Atmosphere - A Review Identifying Research Needs, Polycyclic Aromatic Compounds. 35 (2015) 316-329. https://doi.org/10.1080/10406638.2014.931870.

[15] C. Walgraeve, K. Demeestere, J. Dewulf, R. Zimmermann, H. Van Langenhove, Oxygenated polycyclic aromatic hydrocarbons in atmospheric particulate matter: Molecular characterization and occurrence, Atmospheric Environment. 44 (2010) 1831-1846. https://doi.org/10.1016/j.atmosenv.2009.12.004.

[16] R. Atkinson, J. Arey, Atmospheric Chemistry of Gas-phase Polycyclic Aromatic Hydrocarbons: Formation of Atmospheric Mutagens, Environmental Health Perspectives. 102 (1994) 10. https://dx.doi.org/10.1289/ehp.94102s4117.

[17] Y. Kojima, K. Inazu, Y. Hisamatsu, H. Okochi, T. Baba, T. Nagoya, Influence of secondary formation on atmospheric occurrences of oxygenated polycyclic aromatic hydrocarbons in airborne particles, Atmospheric Environment. 44 (2010) 2873-2880. https://doi.org/10.1016/j.atmosenv.2010.04.048.

[18] I. Abbas, G. Badran, A. Verdin, F. Ledoux, M. Roumié, D. Courcot, G. Garçon, Polycyclic aromatic hydrocarbon derivatives in airborne particulate matter: sources, analysis and toxicity, Environ Chem Lett. 16 (2018) 439-475. https://doi.org/10.1007/s10311-017-0697-0. 
[19] B.A.M. Bandowe, H. Meusel, R. Huang, K. Ho, J. Cao, T. Hoffmann, W. Wilcke, PM2.5-bound oxygenated PAHs, nitro-PAHs and parent-PAHs from the atmosphere of a Chinese megacity: Seasonal variation, sources and cancer risk assessment, Science of The Total Environment. 473-474 (2014) 77-87. https://doi.org/10.1016/j.scitotenv.2013.11.108.

[20] Y. Lin, X. Qiu, Y. Ma, J. Wang, Y. Wu, L. Zeng, M. Hu, T. Zhu, Y. Zhu, A novel approach for apportionment between primary and secondary sources of airborne nitrated polycyclic aromatic hydrocarbons (NPAHs), Atmospheric Environment. 138 (2016) 108-113. https://doi.org/10.1016/j.atmosenv.2016.05.017.

[21] S. Tomaz, J.-L. Jaffrezo, O. Favez, E. Perraudin, E. Villenave, A. Albinet, Sources and atmospheric chemistry of oxy- and nitro-PAHs in the ambient air of Grenoble (France), Atmospheric Environment. 161 (2017) 144-154. https://doi.org/10.1016/j.atmosenv.2017.04.042.

[22] Y. Lin, X. Qiu, Y. Ma, J. Ma, M. Zheng, M. Shao, Concentrations and spatial distribution of polycyclic aromatic hydrocarbons (PAHs) and nitrated PAHs (NPAHs) in the atmosphere of North China, and the transformation from PAHs to NPAHs, Environmental Pollution. 196 (2015) 164-170. https://doi.org/10.1016/j.envpol.2014.10.005.

[23] J. Ringuet, E. Leoz-Garziandia, H. Budzinski, E. Villenave, A. Albinet, Particle size distribution of nitrated and oxygenated polycyclic aromatic hydrocarbons (NPAHs and OPAHs) on traffic and suburban sites of a European megacity: Paris (France), Atmos. Chem. Phys. 12 (2012) 88778887. https://doi.org/10.5194/acp-12-8877-2012.

[24] B. Zielinska, S. Samy, Analysis of nitrated polycyclic aromatic hydrocarbons, Anal Bioanal Chem. 386 (2006) 883-890. https://doi.org/10.1007/s00216-006-0521-3.

[25] H.-Y. Chen, M.R. Preston, Azaarenes in the Aerosol of an Urban Atmosphere, Environ. Sci. Technol. 32 (1998) 577-583. https://doi.org/10.1021/es970033n.

[26] J.F. Collins, J.P. Brown, G.V. Alexeeff, A.G. Salmon, Potency Equivalency Factors for Some Polycyclic Aromatic Hydrocarbons and Polycyclic Aromatic Hydrocarbon Derivatives, Regulatory Toxicology and Pharmacology. 28 (1998) 45-54. https://doi.org/10.1006/rtph.1998.1235.

[27] O. Delhomme, M. Millet, Azaarenes in atmospheric particulate matter samples of three different urban sites in east of France, Atmospheric Environment. 47 (2012) 541-545. https://doi.org/10.1016/j.atmosenv.2011.06.044.

[28] M.L. Lee, M. Novotny, K.D. Bartle, Gas chromatography/mass spectrometric and nuclear magnetic resonance determination of polynuclear aromatic hydrocarbons in airborne particulates, Anal. Chem. 48 (1976) 1566-1572. https://doi.org/10.1021/ac50005a037.

[29] S.G. Mössner, S.A. Wise, Determination of Polycyclic Aromatic Sulfur Heterocycles in Fossil Fuel-Related Samples, Anal. Chem. 71 (1999) 58-69. https://doi.org/10.1021/ac980664f.

[30] IARC, Bitumens and bitumen emissions, and some N- and S-heterocyclic polycyclic aromatic hydrocarbons, International Agency for Research on Cancer, Lyon, 2013.

[31] A. Albinet, E. Leoz-Garziandia, H. Budzinski, E. Villenave, Simultaneous analysis of oxygenated and nitrated polycyclic aromatic hydrocarbons on standard reference material 1649a (urban dust) and on natural ambient air samples by gas chromatography-mass spectrometry with negative ion chemical ionisation, Journal of Chromatography A. 1121 (2006) 106-113. https://doi.org/10.1016/j.chroma.2006.04.043.

[32] J.M. Delgado-Saborit, N. Aquilina, S. Baker, S. Harrad, C. Meddings, R.M. Harrison, Determination of atmospheric particulate-phase polycyclic aromatic hydrocarbons from low volume air samples, Anal. Methods. 2 (2010) 231. https://doi.org/10.1039/b9ay00157c.

[33] G. Karavalakis, G. Deves, G. Fontaras, S. Stournas, Z. Samaras, E. Bakeas, The impact of soybased biodiesel on PAH, nitro-PAH and oxy-PAH emissions from a passenger car operated over regulated and nonregulated driving cycles, Fuel. 89 (2010) 3876-3883. https://doi.org/10.1016/j.fuel.2010.07.002.

[34] W. Lian, F. Ren, L. Tang, D. Dong, Analysis of polycyclic aromatic hydrocarbons in cigarette samples using gel permeation chromatography clean-up by gas chromatography-tandem mass spectrometry, Microchemical Journal. 129 (2016) 194-199. https://doi.org/10.1016/j.microc.2016.06.021.

[35] D.G. Madruga, R.M. Ubeda, J.M. Terroba, S.G. dos Santos, J.P. García-Cambero, Particleassociated polycyclic aromatic hydrocarbons in a representative urban location (indoor-outdoor) from South Europe: Assessment of potential sources and cancer risk to humans, Indoor Air. 29 (2019) 817-827. https://doi.org/10.1111/ina.12581.

[36] M. Tutino, A. Di Gilio, A. Laricchiuta, G. Assennato, G. de Gennaro, An improved method to determine PM-bound nitro-PAHs in ambient air, Chemosphere. 161 (2016) 463-469. https://doi.org/10.1016/j.chemosphere.2016.07.015. 
[37] I.J. Keyte, A. Albinet, R.M. Harrison, On-road traffic emissions of polycyclic aromatic hydrocarbons and their oxy- and nitro- derivative compounds measured in road tunnel environments, Science of The Total Environment. 566-567 (2016) 1131-1142. https://doi.org/10.1016/j.scitotenv.2016.05.152.

[38] M.S. Nocun, M.M. Schantz, Determination of selected oxygenated polycyclic aromatic hydrocarbons (oxy-PAHs) in diesel and air particulate matter standard reference materials (SRMs), Anal Bioanal Chem. 405 (2013) 5583-5593. https://doi.org/10.1007/s00216-013-69573.

[39] T.P. Whitehead, C. Metayer, M. Petreas, M. Does, P.A. Buffler, S.M. Rappaport, Polycyclic Aromatic Hydrocarbons in Residential Dust: Sources of Variability, Environ Health Perspect. 121 (2013) 543-550. https://doi.org/10.1289/ehp.1205821.

[40] J.O. Lalah, P.N. Kaigwara, Polynuclear aromatic compounds in kerosene, diesel and unmodified sunflower oil and in respective engine exhaust particulate emissions, Toxicological \& Environmental Chemistry. 87 (2005) 463-479. https://doi.org/10.1080/02772240500316702.

[41] Y. Lin, Y. Ma, X. Qiu, R. Li, Y. Fang, J. Wang, Y. Zhu, D. Hu, Sources, transformation, and health implications of PAHs and their nitrated, hydroxylated, and oxygenated derivatives in PM 2.5 in Beijing, J. Geophys. Res. Atmos. 120 (2015) 7219-7228. https://doi.org/10.1002/2015JD023628.

[42] D.L. Poster, M.M. Schantz, L.C. Sander, S.A. Wise, Analysis of polycyclic aromatic hydrocarbons (PAHs) in environmental samples: a critical review of gas chromatographic (GC) methods, Anal Bioanal Chem. 386 (2006) 859-881. https://doi.org/10.1007/s00216-006-0771-0.

[43] J.-J. Sauvain, T. Vu-Duc, C.-K. Huynh, Development of an analytical method for the simultaneous determination of 15 carcinogenic polycyclic aromatic hydrocarbons and polycyclic aromatic nitrogen heterocyclic compounds. Application to diesel particulates, Fresenius' Journal of Analytical Chemistry. 371 (2001) 966-974. https://doi.org/10.1007/s002160101047.

[44] ASTM International, Test Method for Determination of Gaseous and Particulate Polycyclic Aromatic Hydrocarbons in Ambient Air (Collection on Sorbent-Backed Filters with Gas Chromatographic/Mass Spectrometric Analysis), ASTM International, West Conshohocken, PA, 2004. https://doi.org/10.1520/D6209-98R04.

[45] European Commity for Standardization, EN 15527:2008 - Characterization of waste Determination of polycyclic aromatic hydrocarbons (PAH) in waste using gas chromatography mass spectrometry (GC/MS), (2008).

[46] International Organization for Standardization, ISO 18287:2006 - Soil quality - Determination of polycyclic aromatic hydrocarbons (PAH) - Gas chromatographic method with mass spectrometric detection (GC-MS), (2006).

[47] U.S. Environmental Protection Agency, Compendium Method TO-13A - Determination of Polycyclic AromaticHydrocarbons (PAHs) in Ambient Air Using Gas Chromatography/Mass Spectrometry (GC/MS), (1999).

[48] Z. Cao, M. Wang, Q. Chen, C. Zhu, J. Jie, X. Li, X. Dong, Z. Miao, M. Shen, Q. Bu, Spatial, seasonal and particle size dependent variations of PAH contamination in indoor dust and the corresponding human health risk, Science of The Total Environment. 653 (2019) 423-430. https://doi.org/10.1016/j.scitotenv.2018.10.413.

[49] Q. Wang, K. Kobayashi, M. Zhou, S. Lu, S. Dong, D. Nakajima, K. Sekiguchi, M. Terasaki, Study on the size-segregated distribution of 37 species of polycyclic aromatic hydrocarbons in urban atmospheric fine particles of Japan, in: WIT Press, Opatija, Croatia, 2014: pp. 131-143. https://doi.org/10.2495/AIR140111.

[50] M. Sklorz, J. Schnelle-Kreis, Y. Liu, J. Orasche, R. Zimmermann, Daytime resolved analysis of polycyclic aromatic hydrocarbons in urban aerosol samples - Impact of sources and meteorological conditions, Chemosphere. 67 (2007) 934-943. https://doi.org/10.1016/j.chemosphere.2006.11.006.

[51] D.L. Poster, M.M. Schantz, S.A. Wise, M.G. Vangel, Analysis of urban particulate standard reference materials for the determination of chlorinated organic contaminants and additional chemical and physical properties, Fresenius' Journal of Analytical Chemistry. 363 (1999) 380390. https://doi.org/10.1007/s002160051207.

[52] S.A. Wise, M.M. Schantz, M.J. Hays, B.J. Koster, K.E. Sharpless, L.C. Sander, B.A. Benner, S.B. Schiller, Certification of Polycyclic Aromatic Hydrocarbons in Mussel Tissue and Air Particulate Standard Reference Materials (SRMs), Polycyclic Aromatic Compounds. 9 (1996) 209-216. https://doi.org/10.1080/10406639608031220.

[53] W.B. Wilson, L.C. Sander, J.O. Oña-Ruales, S.G. Mössner, L.M. Sidisky, M.L. Lee, S.A. Wise, Retention behavior of isomeric polycyclic aromatic sulfur heterocycles in gas chromatography on 
stationary phases of different selectivity, Journal of Chromatography A. 1485 (2017) 120-130. https://doi.org/10.1016/j.chroma.2017.01.024.

[54] K.A. Anderson, M.J. Szelewski, G. Wilson, B.D. Quimby, P.D. Hoffman, Modified ion source triple quadrupole mass spectrometer gas chromatograph for polycyclic aromatic hydrocarbon analyses, Journal of Chromatography A. 1419 (2015) 89-98. https://doi.org/10.1016/j.chroma.2015.09.054.

[55] H.Q. Anh, N.M. Tue, L.H. Tuyen, T.B. Minh, P.H. Viet, S. Takahashi, Polycyclic aromatic hydrocarbons and their methylated derivatives in settled dusts from end-of-life vehicle processing, urban, and rural areas, northern Vietnam: Occurrence, source apportionment, and risk assessment, Science of The Total Environment. 672 (2019) 468-478. https://doi.org/10.1016/j.scitotenv.2019.04.018.

[56] P. Di Filippo, C. Riccardi, C. Gariazzo, F. Incoronato, D. Pomata, S. Spicaglia, A. Cecinato, Air pollutants and the characterization of the organic content of aerosol particles in a mixed industrial/semi-rural area in central Italy, J. Environ. Monit. 9 (2007) 275. https://doi.org/10.1039/b615118c.

[57] C. Bravo-Linares, L. Ovando-Fuentealba, S. Orellana-Donoso, K. Villenas-Fernández, M. Hernández-Millán, S.M. Mudge, J.P. Pinaud-Mendoza, R. Loyola-Sepulveda, Source Apportionment of PAHs in Airborne Particulates (PM 2.5) in Southern Chile, Polycyclic Aromatic Compounds. 37 (2017) 189-202. https://doi.org/10.1080/10406638.2016.1238400.

[58] C. Scipioni, F. Villanueva, K. Pozo, R. Mabilia, Preliminary characterization of polycyclic aromatic hydrocarbons, nitrated polycyclic aromatic hydrocarbons and polychlorinated dibenzo$p$-dioxins and furans in atmospheric PM10 of an urban and a remote area of Chile, Environmental Technology. 33 (2012) 809-820. https://doi.org/10.1080/09593330.2011.597433.

[59] F.M. Norlock, J.-K. Jang, Q. Zou, T.M. Schoonover, A. Li, Large-Volume Injection PTV-GC-MS Analysis of Polycyclic Aromatic Hydrocarbons in Air and Sediment Samples, Journal of the Air \& Waste Management Association. 52 (2002) 19-26. https://doi.org/10.1080/10473289.2002.10470752.

[60] B.A.M. Bandowe, W. Wilcke, Analysis of Polycyclic Aromatic Hydrocarbons and Their OxygenContaining Derivatives and Metabolites in Soils, J. Environ. Qual. 39 (2010) 1349-1358. https://doi.org/10.2134/jeq2009.0298.

[61] R.E. Cochran, N. Dongari, H. Jeong, J. Beránek, S. Haddadi, J. Shipp, A. Kubátová, Determination of polycyclic aromatic hydrocarbons and their oxy-, nitro-, and hydroxy-oxidation products, Analytica Chimica Acta. 740 (2012) 93-103. https://doi.org/10.1016/j.aca.2012.05.050.

[62] B.R.T. Simoneit, X. Bi, D.R. Oros, P.M. Medeiros, G. Sheng, J. Fu, Phenols and Hydroxy-PAHs (Arylphenols) as Tracers for Coal Smoke Particulate Matter: Source Tests and Ambient Aerosol Assessments, Environ. Sci. Technol. 41 (2007) 7294-7302. https://doi.org/10.1021/es071072u.

[63] A. Albinet, F. Nalin, S. Tomaz, J. Beaumont, F. Lestremau, A simple QuEChERS-like extraction approach for molecular chemical characterization of organic aerosols: application to nitrated and oxygenated PAH derivatives (NPAH and OPAH) quantified by GC-NICIMS, Anal Bioanal Chem. 406 (2014) 3131-3148. https://doi.org/10.1007/s00216-014-7760-5.

[64] Z. Kitanovski, P. Shahpoury, C. Samara, A. Voliotis, G. Lammel, Composition and mass size distribution of nitrated and oxygenated aromatic compounds in ambient particulate matter from southern and central Europe - implications for the origin, Atmos. Chem. Phys. 20 (2020) 24712487. https://doi.org/10.5194/acp-20-2471-2020.

[65] Y. Liu, M. Sklorz, J. Schnelle-Kreis, J. Orasche, T. Ferge, A. Kettrup, R. Zimmermann, Oxidant denuder sampling for analysis of polycyclic aromatic hydrocarbons and their oxygenated derivates in ambient aerosol: Evaluation of sampling artefact, Chemosphere. 62 (2006) 18891898. https://doi.org/10.1016/j.chemosphere.2005.07.049.

[66] Y. Han, L. Ren, K. Xu, F. Yang, Y. Li, T. Cheng, X. Kang, C. Xu, Q. Shi, Supercritical fluid extraction with carbon nanotubes as a solid collection trap for the analysis of polycyclic aromatic hydrocarbons and their derivatives, Journal of Chromatography A. 1395 (2015) 1-6. https://doi.org/10.1016/j.chroma.2015.03.038.

[67] G. Lammel, Z. Kitanovski, P. Kukučka, J. Novák, A.M. Arangio, G.P. Codling, A. Filippi, J. Hovorka, J. Kuta, C. Leoni, P. Př́bylová, R. Prokeš, O. Sáňka, P. Shahpoury, H. Tong, M. Wietzoreck, Oxygenated and Nitrated Polycyclic Aromatic Hydrocarbons in Ambient Air-Levels, Phase Partitioning, Mass Size Distributions, and Inhalation Bioaccessibility, Environ. Sci. Technol. 54 (2020) 2615-2625. https://doi.org/10.1021/acs.est.9b06820.

[68] G. Wang, K. Kawamura, X. Zhao, Q. Li, Z. Dai, H. Niu, Identification, abundance and seasonal variation of anthropogenic organic aerosols from a mega-city in China, Atmospheric Environment. 41 (2007) 407-416. https://doi.org/10.1016/j.atmosenv.2006.07.033. 
[69] H.A. Bamford, D.Z. Bezabeh, M.M. Schantz, S.A. Wise, J.E. Baker, Determination and comparison of nitrated-polycyclic aromatic hydrocarbons measured in air and diesel particulate reference materials, Chemosphere. 50 (2003) 575-587. https://doi.org/10.1016/S00456535(02)00667-7.

[70] D.Z. Bezabeh, H.A. Bamford, M.M. Schantz, S.A. Wise, Determination of nitrated polycyclic aromatic hydrocarbons in diesel particulate-related standard reference materials by using gas chromatography/mass spectrometry with negative ion chemical ionization, Anal Bioanal Chem. 375 (2003) 381-388. https://doi.org/10.1007/s00216-002-1698-8.

[71] Y. Gao, L. Yang, J. Chen, Y. Li, P. Jiang, J. Zhang, H. Yu, W. Wang, Nitro and oxy-PAHs bounded in PM2.5 and PM1.0 under different weather conditions at Mount Tai in Eastern China: Sources, long-distance transport, and cancer risk assessment, Science of The Total Environment. 622-623 (2018) 1400-1407. https://doi.org/10.1016/j.scitotenv.2017.11.200.

[72] G. Grimmer, J. Jacob, G. Dettbarn, K.-W. Naujack, Determination of polycyclic aromatic hydrocarbons, azaarenes, and thiaarenes emitted from coal-fired residential furnaces by gas chromatography/mass spectrometry, Z. Anal. Chem. 322 (1985) 595-602. https://doi.org/10.1007/BF00464595.

[73] T. Nielsen, P. Clausen, F.P. Jensen, Determination of basic azaarenes and polynuclear aromatic hydrocarbons in airborne particulate matter by gas chromatography, Analytica Chimica Acta. 187 (1986) 223-231. https://doi.org/10.1016/S0003-2670(00)82914-1.

[74] O. Delhomme, M. Millet, Comparison of Two Analytical Methods for the Determination of Azaarenes in Atmospheric Particulate Matter, Polycyclic Aromatic Compounds. 28 (2008) 518532. https://doi.org/10.1080/10406630802375215.

[75] C.A. Alves, A.M.P. Vicente, J. Gomes, T. Nunes, M. Duarte, B.A.M. Bandowe, Polycyclic aromatic hydrocarbons (PAHs) and their derivatives (oxygenated-PAHs, nitrated-PAHs and azaarenes) in size-fractionated particles emitted in an urban road tunnel, Atmospheric Research. 180 (2016) 128-137. https://doi.org/10.1016/j.atmosres.2016.05.013.

[76] E.D. Vicente, A.M. Vicente, B.A. Musa Bandowe, C.A. Alves, Particulate phase emission of parent polycyclic aromatic hydrocarbons (PAHs) and their derivatives (alkyl-PAHs, oxygenatedPAHs, azaarenes and nitrated PAHs) from manually and automatically fired combustion appliances, Air Qual Atmos Health. 9 (2016) 653-668. https://doi.org/10.1007/s11869-015-03641.

[77] B. Schmid, J.T. Andersson, Critical Examination of the Quantification of Aromatic Compounds in Three Standard Reference Materials, Analytical Chemistry. 69 (1997) 3476-3481. https://doi.org/10.1021/ac970194+.

[78] C. Zeigler, M. Schantz, S. Wise, A. Robbat, Mass Spectra and Retention Indexes for Polycyclic Aromatic Sulfur Heterocycles and Some Alkylated Analogs, Polycyclic Aromatic Compounds. 32 (2012) 154-176. https://doi.org/10.1080/10406638.2011.651679.

[79] T. Vu-Duc, C.-K. Huynh, S. Binet, Laboratory Generated Bitumen Fumes Under Standardized Conditions. Clean-up Scheme and Ion Trap GC-MS Analysis of VOC, Semi-Volatile and Particulate PAH and PASH, Journal of Occupational and Environmental Hygiene. 4 (2007) 245248. https://doi.org/10.1080/15459620701274382.

[80] P.M. Antle, C.D. Zeigler, N.M. Wilton, A. Robbat, Jr., A more accurate analysis of alkylated PAH and PASH and its implications in environmental forensics, International Journal of Environmental Analytical Chemistry. 94 (2014) 332-347. https://doi.org/10.1080/03067319.2013.840886.

[81] F. Liang, M. Lu, M.E. Birch, T.C. Keener, Z. Liu, Determination of polycyclic aromatic sulfur heterocycles in diesel particulate matter and diesel fuel by gas chromatography with atomic emission detection, Journal of Chromatography A. 1114 (2006) 145-153. https://doi.org/10.1016/j.chroma.2006.02.096.

[82] J.T. Andersson, A.H. Hegazi, B. Roberz, Polycyclic aromatic sulfur heterocycles as information carriers in environmental studies, Anal Bioanal Chem. 386 (2006) 891-905. https://doi.org/10.1007/s00216-006-0704-y.

[83] C.T. Pham, T. Kameda, A. Toriba, K. Hayakawa, Polycyclic aromatic hydrocarbons and nitropolycyclic aromatic hydrocarbons in particulates emitted by motorcycles, Environmental Pollution. 183 (2013) 175-183. https://doi.org/10.1016/j.envpol.2013.01.003.

[84] G. Sangiorgi, L. Ferrero, B.S. Ferrini, C. Lo Porto, M.G. Perrone, R. Zangrando, A. Gambaro, Z. Lazzati, E. Bolzacchini, Indoor airborne particle sources and semi-volatile partitioning effect of outdoor fine PM in offices, Atmospheric Environment. 65 (2013) 205-214. https://doi.org/10.1016/j.atmosenv.2012.10.050.

[85] S.A. Wise, L.R. Hilpert, G.D. Byrd, W.E. May, Comparison of Liquid Chromatography with Fluorescence Detection and Gas Chromatography/Mass Spectrometry for the Determination of 
Polycyclic Aromatic Hydrocarbons in Environmental Samples, Polycyclic Aromatic Compounds. 1 (1990) 81-98. https://doi.org/10.1080/10406639008034751.

[86] D. Castro, K. Slezakova, C. Delerue-Matos, M. da C. Alvim-Ferraz, S. Morais, M. do C. Pereira, Polycyclic aromatic hydrocarbons in gas and particulate phases of indoor environments influenced by tobacco smoke: Levels, phase distributions, and health risks, Atmospheric Environment. 45 (2011) 1799-1808. https://doi.org/10.1016/j.atmosenv.2011.01.018.

[87] C. Liaud, M. Millet, S. Le Calvé, An analytical method coupling accelerated solvent extraction and HPLC-fluorescence for the quantification of particle-bound PAHs in indoor air sampled with a 3-stages cascade impactor, Talanta. 131 (2015) 386-394. https://doi.org/10.1016/j.talanta.2014.05.027.

[88] S. Tomaz, P. Shahpoury, J.-L. Jaffrezo, G. Lammel, E. Perraudin, E. Villenave, A. Albinet, Oneyear study of polycyclic aromatic compounds at an urban site in Grenoble (France): Seasonal variations, gas/particle partitioning and cancer risk estimation, Science of The Total Environment. 565 (2016) 1071-1083. https://doi.org/10.1016/j.scitotenv.2016.05.137.

[89] G. De Guidi, V. Librando, Z. Minniti, E. Bolzacchini, G. Perrini, G. Bracchitta, A. Alparone, A. Catalfo, The PAH and Nitro-PAH Concentration Profiles in Size-Segregated Urban Particulate Matter and Soil in Traffic-Related Sites in Catania, Italy, Polycyclic Aromatic Compounds. 32 (2012) 439-456. https://doi.org/10.1080/10406638.2011.654306.

[90] A.I. Barrado-Olmedo, R.M. Pérez-Pastor, S. García-Alonso, An evaluation of uncertainty associated to analytical measurements of selected polycyclic aromatic compounds in ambient air, Talanta. 101 (2012) 428-434. https://doi.org/10.1016/j.talanta.2012.09.053.

[91] N. Kishikawa, S. Morita, M. Wada, Y. Ohba, K. Nakashima, N. Kuroda, Determination of Hydroxylated Polycyclic Aromatic Hydrocarbons in Airborne Particulates by High-Performance Liquid Chromatography with Fluorescence Detection, Anal. Sci. 20 (2004) 129-132. https://doi.org/10.2116/analsci.20.129.

[92] O. Delhomme, M. Millet, P. Herckes, Determination of oxygenated polycyclic aromatic hydrocarbons in atmospheric aerosol samples by liquid chromatography-tandem mass spectrometry, Talanta. 74 (2008) 703-710. https://doi.org/10.1016/j.talanta.2007.06.037.

[93] T. Letzel, E. Rosenberg, R. Wissiack, M. Grasserbauer, R. Niessner, Separation and identification of polar degradation products of benzo[a]pyrene with ozone by atmospheric pressure chemical ionization-mass spectrometry after optimized column chromatographic cleanup, Journal of Chromatography A. 855 (1999) 501-514. https://doi.org/10.1016/S00219673(99)00716-5.

[94] J. Lintelmann, K. Fischer, E. Karg, A. Schröppel, Determination of selected polycyclic aromatic hydrocarbons and oxygenated polycyclic aromatic hydrocarbons in aerosol samples by highperformance liquid chromatography and liquid chromatography?tandem mass spectrometry, Anal Bioanal Chem. 381 (2005) 508-519. https://doi.org/10.1007/s00216-004-2883-8.

[95] T. Letzel, U. Pöschl, R. Wissiack, E. Rosenberg, M. Grasserbauer, R. Niessner, Phenyl-Modified Reversed-Phase Liquid Chromatography Coupled to Atmospheric Pressure Chemical Ionization Mass Spectrometry: A Universal Method for the Analysis of Partially Oxidized Aromatic Hydrocarbons, Anal. Chem. 73 (2001) 1634-1645. https://doi.org/10.1021/ac001079t.

[96] S. Grosse, T. Letzel, Liquid chromatography/atmospheric pressure ionization mass spectrometry with post-column liquid mixing for the efficient determination of partially oxidized polycyclic aromatic hydrocarbons, Journal of Chromatography A. 1139 (2007) 75-83. https://doi.org/10.1016/j.chroma.2006.10.086.

[97] K. Hayakawa, N. Tang, K. Akutsu, T. Murahashi, H. Kakimoto, R. Kizu, A. Toriba, Comparison of polycyclic aromatic hydrocarbons and nitropolycyclic aromatic hydrocarbons in airborne particulates collected in downtown and suburban Kanazawa, Japan, Atmospheric Environment. 36 (2002) 5535-5541. https://doi.org/10.1016/S1352-2310(02)00252-2.

[98] C. Schauer, R. Niessner, U. Pöschl, Analysis of nitrated polycyclic aromatic hydrocarbons by liquid chromatography with fluorescence and mass spectrometry detection: air particulate matter, soot, and reaction product studies, Analytical and Bioanalytical Chemistry. 378 (2004) 725-736. https://doi.org/10.1007/s00216-003-2449-1.

[99] O. Delhomme, P. Herckes, M. Millet, Determination of nitro-polycyclic aromatic hydrocarbons in atmospheric aerosols using HPLC fluorescence with a post-column derivatisation technique, Anal Bioanal Chem. 389 (2007) 1953-1959. https://doi.org/10.1007/s00216-007-1562-y.

[100] J. Lintelmann, M.H. França, E. Hübner, G. Matuschek, A liquid chromatography-atmospheric pressure photoionization tandem mass spectrometric method for the determination of azaarenes in atmospheric particulate matter, Journal of Chromatography A. 1217 (2010) 1636-1646. https://doi.org/10.1016/j.chroma.2010.01.029. 
[101] W.B. Wilson, L.C. Sander, M. Lopez de Alda, M.L. Lee, S.A. Wise, Retention behavior of isomeric polycyclic aromatic sulfur heterocycles in reversed-phase liquid chromatography, J. Chromatogr. A. 1461 (2016) 107-119. https://doi.org/10.1016/j.chroma.2016.07.064.

[102] A. Fushimi, S. Hashimoto, T. leda, N. Ochiai, Y. Takazawa, Y. Fujitani, K. Tanabe, Thermal desorption - comprehensive two-dimensional gas chromatography coupled with tandem mass spectrometry for determination of trace polycyclic aromatic hydrocarbons and their derivatives, J. Chromatogr. A. 1252 (2012) 164- 170. https://doi.org/10.1016/j.chroma.2012.06.068.

[103] C. Manzano, E. Hoh, S.L.M. Simonich, Quantification of complex polycyclic aromatic hydrocarbon mixtures in standard reference materials using comprehensive two-dimensional gas chromatography with time-of-flight mass spectrometry, J. Chromatogr. A. 1307 (2013) 172- 179. https://doi.org/10.1016/j.chroma.2013.07.093.

[104] C. Manzano, E. Hoh, S.L.M. Simonich, Improved Separation of Complex Polycyclic Aromatic Hydrocarbon Mixtures Using Novel Column Combinations in GC × GC/ToF-MS, Environ. Sci. Technol. 46 (2012) 7677-7684. https://doi.org/10.1021/es301790h.

[105] A. Christensen, C. Östman, R. Westerholm, Ultrasound-assisted extraction and on-line LCGC/MS for determination of polycyclic aromatic hydrocarbons (PAH) in urban dust and diesel particulate matter, Anal Bioanal Chem. 381 (2005) 1206-1216. https://doi.org/10.1007/s00216005-3065-z.

[106] S. Masala, H. Lim, C. Bergvall, C. Johansson, R. Westerholm, Determination of semi-volatile and particle-associated polycyclic aromatic hydrocarbons in Stockholm air with emphasis on the highly carcinogenic dibenzopyrene isomers, Atmospheric Environment. 140 (2016) 370-380. https://doi.org/10.1016/j.atmosenv.2016.06.007.

[107] P. Tollbäck, H. Carlsson, C. Östman, Coupled LC-GC-NPD for Determination of Carbazole-Type PANH and Its Application to Personal Exposure Measurement, J. High Resol. Chromatogr. 23 (2000) 131-137.

[108] C.A. Alves, A.M. Vicente, D. Custódio, M. Cerqueira, T. Nunes, C. Pio, F. Lucarelli, G. Calzolai, S. Nava, E. Diapouli, K. Eleftheriadis, X. Querol, B.A. Musa Bandowe, Polycyclic aromatic hydrocarbons and their derivatives (nitro-PAHs, oxygenated PAHs, and azaarenes) in PM 2.5 from Southern European cities, Science of The Total Environment. 595 (2017) 494-504. https://doi.org/10.1016/j.scitotenv.2017.03.256.

[109] F. Villanueva, G. Sevilla, S. Lara, P. Martín, S. Salgado, J. Albaladejo, B. Cabañas, Application of gas chromatography coupled with tandem mass spectrometry for the assessment of PAH levels in non industrial indoor air, Microchemical Journal. 142 (2018) 117-125. https://doi.org/10.1016/j.microc.2018.06.021.

[110] C. Chiu, W. Miles, An Improved Method for Nitro-PAH Analysis, Polycyclic Aromatic Compounds. 9 (1996) 307-314. https://doi.org/10.1080/10406639608031232.

[111] W. Du, Y. Chen, G. Shen, W. Wang, S. Zhuo, Y. Huang, X. Pan, S. Tao, Winter air pollution by and inhalation exposure to nitrated and oxygenated PAHs in rural Shanxi, north China, Atmospheric Environment. 187 (2018) 210-217. https://doi.org/10.1016/j.atmosenv.2018.06.004.

[112] G. Gbeddy, P. Egodawatta, A. Goonetilleke, G. Ayoko, L. Chen, Application of quantitative structure-activity relationship (QSAR) model in comprehensive human health risk assessment of PAHs, and alkyl-, nitro-, carbonyl-, and hydroxyl-PAHs laden in urban road dust, Journal of Hazardous Materials. 383 (2020) 121-154. https://doi.org/10.1016/j.jhazmat.2019.121154.

[113] J.H. Gross, Mass Spectrometry - A Textbook, Third Edition, Springer International Publishing, Cham, 2017. https://doi.org/10.1007/978-3-319-54398-7.

[114] D.-X. Li, L. Gan, A. Bronja, O.J. Schmitz, Gas chromatography coupled to atmospheric pressure ionization mass spectrometry (GC-API-MS): Review, Analytica Chimica Acta. 891 (2015) 43-61. https://doi.org/10.1016/j.aca.2015.08.002.

[115] S. Große Brinkhaus, J.B. Thiäner, C. Achten, Ultra-high sensitive PAH analysis of certified reference materials and environmental samples by GC-APLI-MS, Anal Bioanal Chem. 409 (2017) 2801-2812. https://doi.org/10.1007/s00216-017-0224-y.

[116] R. Schiewek, M. Schellenträger, R. Mönnikes, M. Lorenz, R. Giese, K.J. Brockmann, S. Gäb, Th. Benter, O.J. Schmitz, Ultrasensitive Determination of Polycyclic Aromatic Compounds with Atmospheric-Pressure Laser Ionization as an Interface for GC/MS, Anal. Chem. 79 (2007) 41354140. https://doi.org/10.1021/ac0700631.

[117] M. Constapel, M. Schellenträger, O.J. Schmitz, S. Gäb, K.J. Brockmann, R. Giese, Th. Benter, Atmospheric-pressure laser ionization: a novel ionization method for liquid chromatography/mass spectrometry: Atmospheric-pressure laser ionization, Rapid Commun. Mass Spectrom. 19 (2005) 326-336. https://doi.org/10.1002/rcm.1789. 
[118] H. Hayen, U. Karst, Strategies for the liquid chromatographic-mass spectrometric analysis of non-polar compounds, Journal of Chromatography A. 1000 (2003) 549-565. https://doi.org/10.1016/S0021-9673(03)00505-3.

[119] J.B. Thiäner, C. Achten, Liquid chromatography-atmospheric pressure laser ionization-mass spectrometry (LC-APLI-MS) analysis of polycyclic aromatic hydrocarbons with 6-8 rings in the environment, Anal Bioanal Chem. 409 (2017) 1737-1747. https://doi.org/10.1007/s00216-0160121-9.

[120] M.H. Stockett, M. Gatchell, N. de Ruette, L. Giacomozzi, T. Chen, P. Rousseau, S. Maclot, J.-Y. Chesnel, L. Adoui, B.A. Huber, U. Bērziņš, H.T. Schmidt, H. Zettergren, H. Cederquist, Isomer effects in fragmentation of Polycyclic Aromatic Hydrocarbons, International Journal of Mass Spectrometry. 392 (2015) 58-62. https://doi.org/10.1016/j.ijms.2015.09.005.

[121] J.O. Allen, N.M. Dookeran, K. Taghizadeh, A.L. Lafleur, K.A. Smith, A.F. Sarofim, Measurement of Oxygenated Polycyclic Aromatic Hydrocarbons Associated with a Size-Segregated Urban Aerosol, Environ. Sci. Technol. 31 (1997) 2064-2070. https://doi.org/10.1021/es960894g.

[122] F.A. Franchina, M.E. Machado, P.Q. Tranchida, C.A. Zini, E.B. Caramão, L. Mondello, Determination of aromatic sulphur compounds in heavy gas oil by using (low-)flow modulated comprehensive two-dimensional gas chromatography-triple quadrupole mass spectrometry, Journal of Chromatography A. 1387 (2015) 86-94. https://doi.org/10.1016/j.chroma.2015.01.082.

[123] R.D. Cox, R.F. Earp, Determination of trace level organics in ambient air by high-resolution gas chromatography with simultaneous photoionization and flame ionization detection, Anal. Chem. 54 (1982) 2265-2270. https://doi.org/10.1021/ac00250a029.

[124] D.L. Poster, L.C. Sander, S.A. Wise, Chromatographic Methods of Analysis for the Determination of PAHs in Environmental Samples, in: A.H. Neilson (Ed.), PAHs and Related Compounds, Springer Berlin Heidelberg, Berlin, Heidelberg, 1998: pp. 77-135. https://doi.org/10.1007/978-3-540-49697-7_3.

[125] T.T.T. Dong, B.-K. Lee, Characteristics, toxicity, and source apportionment of polycylic aromatic hydrocarbons (PAHs) in road dust of Ulsan, Korea, Chemosphere. 74 (2009) 1245-1253. https://doi.org/10.1016/j.chemosphere.2008.11.035.

[126] S.A. Wise, L.C. Sander, W.E. May, Determination of polycyclic aromatic hydrocarbons by liquid chromatography, Journal of Chromatography A. 642 (1993) 329-349. https://doi.org/10.1016/0021-9673(93)80097-R.

[127] K. Hayakawa, Chromatographic methods for carcinogenic/mutagenic nitropolycyclic aromatic hydrocarbons, Biomed. Chromatogr. 14 (2000) 9. https://doi.org/10.1002/10990801(200010)14:6\%3C397::aid-bmc27\%3E3.0.co;2-o.

[128] N. Ali, Polycyclic aromatic hydrocarbons (PAHs) in indoor air and dust samples of different Saudi microenvironments; health and carcinogenic risk assessment for the general population, Science of The Total Environment. 696 (2019) 133995. https://doi.org/10.1016/j.scitotenv.2019.133995.

[129] M.R. Cave, J. Wragg, D.J. Beriro, C. Vane, R. Thomas, M. Riding, C. Taylor, An overview of research and development themes in the measurement and occurrences of polyaromatic hydrocarbons in dusts and particulates, Journal of Hazardous Materials. 360 (2018) 373-390. https://doi.org/10.1016/j.jhazmat.2018.08.038.

[130] X. Niu, S.S.H. Ho, K.F. Ho, Y. Huang, J. Sun, Q. Wang, Y. Zhou, Z. Zhao, J. Cao, Atmospheric levels and cytotoxicity of polycyclic aromatic hydrocarbons and oxygenated-PAHs in PM2.5 in the Beijing-Tianjin-Hebei region, Environmental Pollution. 231 (2017) 1075-1084. https://doi.org/10.1016/j.envpol.2017.08.099.

[131] C. Wei, Y. Han, B.A.M. Bandowe, J. Cao, R.-J. Huang, H. Ni, J. Tian, W. Wilcke, Occurrence, gas/particle partitioning and carcinogenic risk of polycyclic aromatic hydrocarbons and their oxygen and nitrogen containing derivatives in Xi'an, central China, Science of The Total Environment. 505 (2015) 814-822. https://doi.org/10.1016/j.scitotenv.2014.10.054.

[132] J. Zhang, W. Liu, Y. Xu, C. Cai, Y. Liu, S. Tao, W. Liu, Distribution characteristics of and personal exposure with polycyclic aromatic hydrocarbons and particulate matter in indoor and outdoor air of rural households in Northern China, Environmental Pollution. 255 (2019) 113176. https://doi.org/10.1016/j.envpol.2019.113176.

[133] H. Wingfors, L. Hägglund, R. Magnusson, Characterization of the size-distribution of aerosols and particle-bound content of oxygenated PAHs, PAHs, and n-alkanes in urban environments in Afghanistan, Atmospheric Environment. 45 (2011) 4360-4369. https://doi.org/10.1016/j.atmosenv.2011.05.049.

[134] H.-H. Kim, G.-W. Lee, J.-Y. Yang, J.-M. Jeon, W.-S. Lee, J.-Y. Lim, H.-S. Lee, Y.-K. Gwak, D.-C. Shin, Y.-W. Lim, Indoor Exposure and Health Risk of Polycyclic Aromatic Hydrocarbons (PAHs) 
via Public Facilities PM2.5, Korea (II), Asian Journal of Atmospheric Environment. 8 (2014) 3547. https://doi.org/10.5572/ajae.2014.8.1.035.

[135] J.M. Delgado-Saborit, C. Stark, R.M. Harrison, Carcinogenic potential, levels and sources of polycyclic aromatic hydrocarbon mixtures in indoor and outdoor environments and their implications for air quality standards, Environment International. 37 (2011) 383-392. https://doi.org/10.1016/j.envint.2010.10.011.

[136] C. Liaud, T. Dintzer, V. Tschamber, G. Trouve, S. Le Calvé, Particle-bound PAHs quantification using a 3-stages cascade impactor in French indoor environments, Environmental Pollution. 195 (2014) 64-72. https://doi.org/10.1016/j.envpol.2014.08.007.

[137] E. Hoh, R.N. Hunt, P.J.E. Quintana, J.M. Zakarian, D.A. Chatfield, B.C. Wittry, E. Rodriguez, G.E. Matt, Environmental Tobacco Smoke as a Source of Polycyclic Aromatic Hydrocarbons in Settled Household Dust, Environ. Sci. Technol. 46 (2012) 4174-4183. https://doi.org/10.1021/es300267g.

[138] M.S. Peixoto, F.C. da Silva Junior, M.F. de Oliveira Galvão, D.A. Roubicek, N. de Oliveira Alves, S.R. Batistuzzo de Medeiros, Oxidative stress, mutagenic effects, and cell death induced by retene, Chemosphere. 231 (2019) 518-527. https://doi.org/10.1016/j.chemosphere.2019.05.123.

[139] A.L. Robinson, R. Subramanian, N.M. Donahue, A. Bernardo-Bricker, W.F. Rogge, Source Apportionment of Molecular Markers and Organic Aerosol. 1. Polycyclic Aromatic Hydrocarbons and Methodology for Data Visualization, Environ. Sci. Technol. 40 (2006) 7803-7810. https://doi.org/10.1021/es0510414.

[140] K. Slezakova, J.C.M. Pires, D. Castro, M.C.M. Alvim-Ferraz, C. Delerue-Matos, S. Morais, M.C. Pereira, $\mathrm{PAH}$ air pollution at a Portuguese urban area: carcinogenic risks and sources identification, Environ Sci Pollut Res. 20 (2013) 3932-3945. https://doi.org/10.1007/s11356-0121300-7.

[141] P. Di Filippo, C. Riccardi, D. Pomata, F. Buiarelli, Concentrations of PAHs, and nitro- and methyl- derivatives associated with a size-segregated urban aerosol, Atmospheric Environment. 44 (2010) 2742-2749. https://doi.org/10.1016/j.atmosenv.2010.04.035.

[142] S. Richter-Brockmann, C. Achten, Analysis and toxicity of $59 \mathrm{PAH}$ in petrogenic and pyrogenic environmental samples including dibenzopyrenes, $7 \mathrm{H}$-benzo[c]fluorene, 5-methylchrysene and 1-methylpyrene, Chemosphere. 200 (2018) 495-503. https://doi.org/10.1016/j.chemosphere.2018.02.146.

[143] I.C.T. Nisbet, P.K. LaGoy, Toxic equivalency factors (TEFs) for polycyclic aromatic hydrocarbons (PAHs), Regulatory Toxicology and Pharmacology. 16 (1992) 290-300. https://doi.org/10.1016/0273-2300(92)90009-X.

[144] Y. Ma, Y. Cheng, X. Qiu, Y. Lin, J. Cao, D. Hu, A quantitative assessment of source contributions to fine particulate matter (PM2.5)-bound polycyclic aromatic hydrocarbons (PAHs) and their nitrated and hydroxylated derivatives in Hong Kong, Environmental Pollution. 219 (2016) 742-749. https://doi.org/10.1016/j.envpol.2016.07.034.

[145] B.A.M. Bandowe, H. Meusel, R. Huang, T. Hoffmann, J. Cao, K. Ho, Azaarenes in fine particulate matter from the atmosphere of a Chinese megacity, Environ Sci Pollut Res. 23 (2016) 16025-16036. https://doi.org/10.1007/s11356-016-6740-z. 


\section{Figures}

\section{Figure 1}

Comparison of separation of 20 azaarenes obtained with: a) a GC-MS method with a $50 \%$ trifluoropropyl, $50 \%$ methylpolysiloxane column $(30 \mathrm{~m} \times 0.32 \mathrm{~mm} \times 0.25 \mu \mathrm{m})$ (total analysis

1748 time $=30 \mathrm{~min}$ ), and b) a LC-FLD method with a $\mathrm{C}_{18}-\mathrm{PAH}$ column $(250 \mathrm{~mm} \times 4 \mathrm{~mm}$ i.d.) (total 1749 analysis time $=35 \mathrm{~min}$ ).

1750 In c), LC-FLD chromatogram (b) is zoomed in on co-eluting peaks (resolution inferior to 1.5).

1751 Adapted from Delhomme and Millet [74].
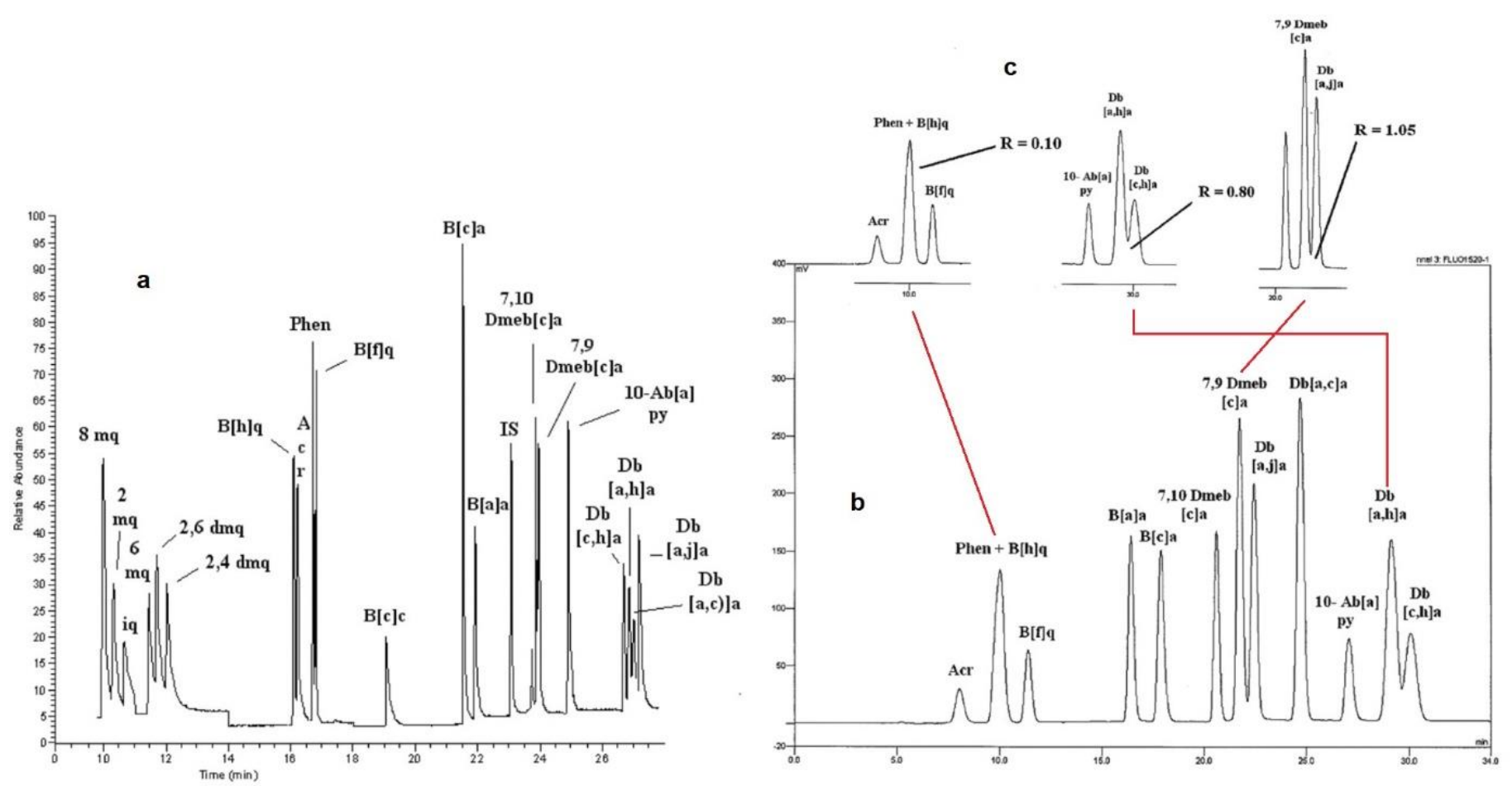
Range of data reported in abstracts dealing with PAH levels where units of $\mathrm{ng} \cdot \mathrm{m}^{-3}$ are used. A "count" refers to the occurrence of a value inside a range in one of the reviewed abstracts. To obtain these data, around 3000 articles about PAHs were reviewed by data and text mining. Reproduced from Cave et al. [129].

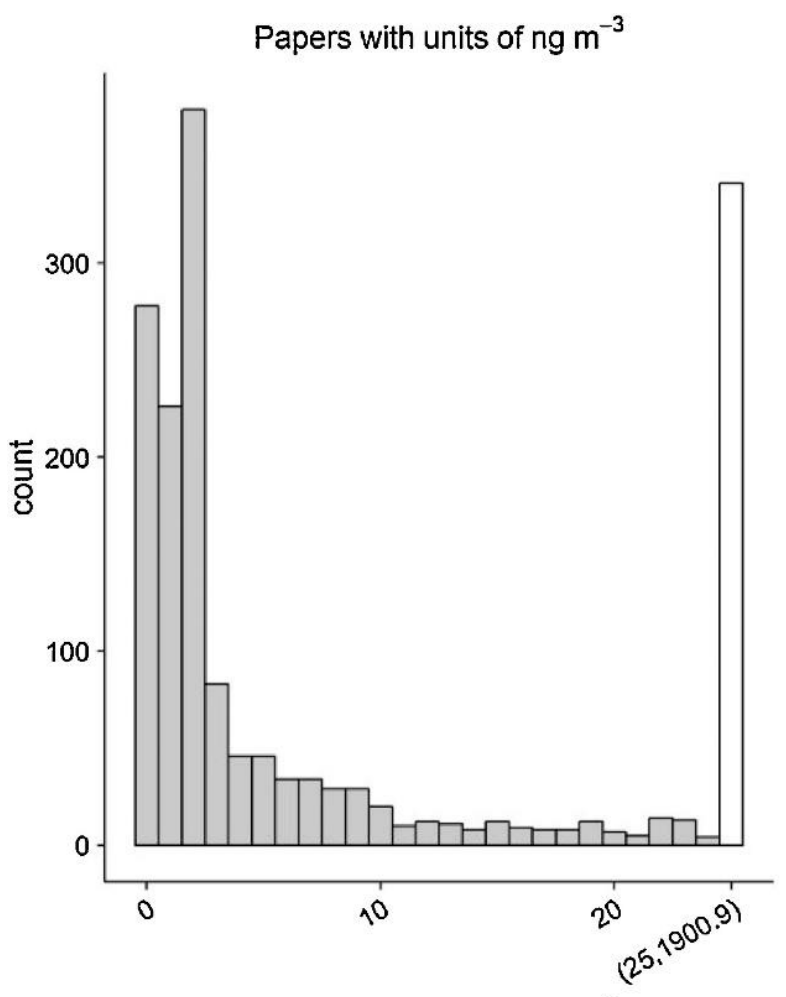

$\mathrm{PAH}$ concentration $\mathrm{ng} \mathrm{m}^{-3}$

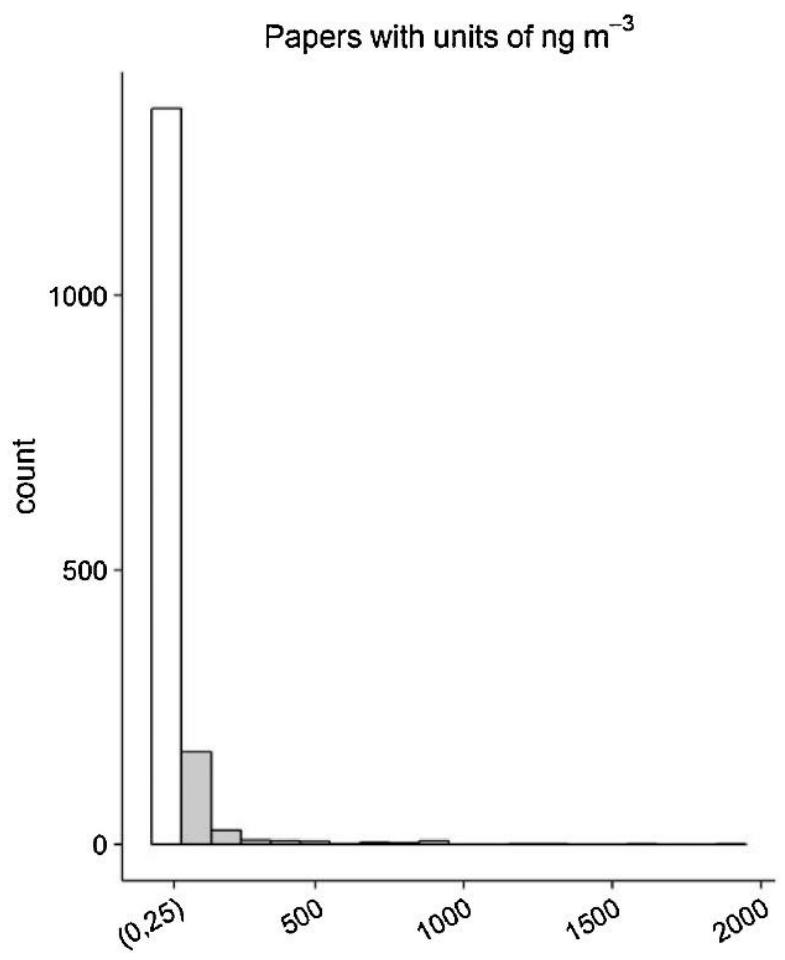

$\mathrm{PAH}$ concentration $\mathrm{ng} \mathrm{m}^{-3}$ 